\title{
ГОРОДА-МИЛЛИОННИКИ НА КАРТЕ СМЕРТНОСТИ РОССИИ
}

\author{
АЛЕКСЕЙ ЩУР
}

\begin{abstract}
Проблема избыточной смертности в России не теряет своей актуальности. Ситуация осложняется и высоким уровнем пространственного неравенства в здоровье, которое в намей стране принято измерять на региональном уровне. Данная работа - одна из первых попыток взглянуть на динамику и размах географического неравенства в здоровье в России на субрегиональном уровне через призму противопоставления «центра» (в намем случае городовмиллионников) и «периферии» (остальной территории страны). Города-миллионники были выбраны не случайно, а исходя из сложивщейся в России пространственной иерархии, согласно которой самый высокий уровень сочиально-экономического развития отмечается в крупнейших городах страны. Более высокому уровню развития человеческого капитала, как правило, соответствует более низкий уровень смертности. Используя данные Росстата, мы рассчитали значения ожидаемой продолжительности жизни при рождении для российских городов-миллионников за 1989-2016 г2. Полученные результаты показали, что на протяжении последней четверти века поляризация в уровне здоровья между городами-миллионниками и остальной территорией России значительно усилилась, став отображением центростремительных процессов, происходящих в нашем Отечестве в этот период. Будучи центрами притяжения внутренних и внешних мигрантов, города-миллионники, как результат, аккумулируют значительно более образованное население, что, безусловно, является важным преимуществом больших городов над «периферией» не только на экономическом фронте, но и в уровне здоровья их жителей, так как людей с высшим образованием отличает более бережное отношение к своему здоровью. Без решения структурных проблем, сдерживаюших соииально-экономическое развитие за пределами крупнейших агломераиий, едва ли возможна конвергениия в уровне смертности между городами-миллионниками и окружающими их территориями.
\end{abstract}

Ключевые слова: продолжительность жизни, пространственное неравенство в смертности, города-миллионники, уровень образования, центр и периферия.

\section{ВВЕДЕНИЕ}

Неравенство в уровне здоровья, как и любой другой вид социально-экономического, т.е. модифицируемого неравенства, - серьезный вызов, стоящий перед государством и обществом [Шкаратан 2009: 556]. В исследованиях неравенства рассматриваются два основных вида различий: межиндивидуальные и межгрупповые [Andreev et al. 2001]. К последним относят неравенство между социально-демографическими группами (в зависимости от пола, расы, национальности, уровня образования, экономического положения, брачного статуса), а также пространственное (географическое) неравенство между странами, типами поселений (например, городской и сельской местностью), регионами и другими более дробными единицами административно-территориального деления.

\footnotetext{
АЛЕКСЕЙ ЕВГЕНЬЕВИЧ ЩУР (aschur@hse.ru), НАЦИОНАЛЬНЫЙ ИССЛЕДОВАТЕЛЬСКИЙ УНИВЕРСИТЕТ «ВЫСШАЯ школА ЭКОНОМики», РосСия.
}

ИССЛЕДОВАНИЕ ФИНАНСИРОВАЛОСЬ В РАМКАХ ПРОГРАММЫ ГОСУДАРСТВЕННОЙ ПОДДЕРЖКИ ВЕДУЩИХ УНИВЕРСИТЕТОВ РОССИЙСКОЙ ФЕДЕРАЦИИ « $5-100 »$.

СТАТЬЯ ПОСТУПИЛА В РЕДАКЦИЮ В АВГУСТЕ 2018 Г. 
Изучение неравенства в смертности особенно актуально для России, отличающейся значительными гендерными различиями в ожидаемой продолжительности жизни (ОПЖ), существенной региональной дифференциацией, а также одним из самых значительных в мире (для стран с достоверной статистикой смертности) различий в ОПЖ между образовательными группами [Shkolnikov et al. 2006; Неравенство и смертность... 2000]. При этом Россия по ожидаемой продолжительности жизни при рождении сильно отстает не только от большинства развитых стран, но и от многих развивающихся [WHO Mortality Database 2017]. Уровню экономического благосостояния России должна соответствовать гораздо большая ожидаемая продолжительность жизни [Андреев, Школьников 2018]. В этой связи изучение уровня неравенства в здоровье и объясняющих его факторов должно помочь пролить свет на причины отставания России в уровне продолжительности жизни от других стран и выделить «передовые» группы, способные указать на механизмы снижения смертности для «остального населения».

Отставание России от мировых стран-лидеров по величине ожидаемой продолжительности жизни начало нарастать с конца 1960-х годов и свидетельствовало о накопившихся внутри советской системы структурных противоречиях [Eberstadt 1981; Вишневский, Школьников 1997]. СССР, как и весь «Восточный блок», оказался не готов противостоять новым угрозам, вызванным изменившейся эпидемиологической ситуацией - увеличением роли неинфекционных причин смерти. Причем, в отличие от многих других стран Восточной Европы, в 1990-е годы «молодой» России так и не удалось вступить в новый этап эпидемиологического перехода; более того, в стране произошло серьезное ухудшение состояния здоровья, заставившее некоторых исследователей даже говорить об «обратном эпидемиологическом переходе» [Семенова 2005: 235].

Современный этап снижения смертности в России, начавшийся с середины 2000-х годов, трактуется специалистами по-разному. Часть демографов считает, что увеличение ожидаемой продолжительности жизни в настоящий период носит восстановительный «компенсационный характер» и пока нет оснований говорить о начале второго эпидемиологического перехода в России [Вишневский 2014]. Другие ученые, напротив, отмечают новые тенденции смертности в стране, которые могут рассматриваться как признаки кардиоваскулярной революции [Grigoriev et al. 2014]. Ответить на вопрос, являются ли происходящие изменения в режиме смертности предвестниками начала второго эпидемиологического перехода, по нашему мнению, может помочь изучение тенденций смертности на территориях, находящихся в авангарде ее снижения в России.

Значительная пространственная поляризация в уровне смертности, особенно в периоды ее резкого подъема или, наоборот, быстрого снижения, отмечалась во многих восточноевропейских странах, которые, так же, как и Россия, во второй половине XX века переживали «кризис смертности». Так, в Литве самая высокая продолжительность жизни в 1988-96 гг. была в крупнейших городах, причем разрыв в уровне смертности между городской и сельской местностью в период социально-экономической трансформации увеличивался [Kalediene, Petrauskiene 2000; Kalediene, Petrauskiene 2004]. Похожая картина наблюдалась и в двух других странах Балтии [Krumins et al 2009]. В Белоруссии, пожалуй, самом близком к России в социально-культурном плане государстве, со второй половины 1990-х годов отмечается ярко выраженная тенденция к дивергенции в уровне смертности 
между столицей и всей остальной страной. В этот же период аналогичный процесс имел место и в нашей стране. Анализ смертности на внутрирегиональном уровне, проведенный для Белоруссии Павлом Григорьевым и соавторами, показал, что во всех областных центрах, a также в других крупнейших городах, являющихся отдельными административными единицами второго уровня (аналог российских районов и городских округов), уровень смертности существенно ниже, чем на окружающих их территориях [Grigoriev, Doblhammer-Reiter, Shkolnikov 2013]. Есть все основания полагать, что схожая картина наблюдается и в России.

Исходя из больших размеров России и ее климатического, социальноэкономического, этнического и другого разнообразия, отечественные и зарубежные ученые уделяют особое внимание изучению тенденций и масштабов различий в уровне смертности в региональном разрезе [Vasin, Costello 1997; Shkolnikov, Vasin 1994; Vallin et al. 2005; Timonin et al. 2017]. Так, еще в советское время было показано, что в России (РСФСР) существовал юго-западный/северо-восточный градиент смертности [Андреев 1979; Школьников 1987], который остается актуальным и по сей день [Timonin et al. 2017]. Кроме того, как правило, отмечается особое «привилегированное» место на «карте смертности» России Санкт-Петербурга и, особенно, Москвы, тенденции и уровень смертности в которых часто противопоставляются общероссийским [Андреев, Кваша, Харькова 2006; Кваша, Харькова 2009]. При этом Москва и Санкт-Петербург, несмотря на все недавние успехи в снижении смертности, значительно отстают по уровню ожидаемой продолжительности жизни от западных мегаполисов [Андреев, Кваша, Харькова 2016].

Социально-экономическое положение и образовательный состав населения действительно отличают бывшую и нынешнюю столицы России от остальной ее территории, вместе с тем другие крупнейшие населенные пункты страны, в первую очередь города с численностью населения свыше одного миллиона человек, также очень часто рассматриваются как опорные точки модернизации страны, ее образовательные и экономические центры, места притяжения людей [Зубаревич 2010]. В этой связи представляется интересным провести сравнительный анализ основных тенденций смертности в двух столицах, а также в других «нестоличных» городах-миллионниках в сравнении с окружающими их территориями (регионами, административными центрами которых они являются), а также с остальной территорией страны. Это поможет ответить на вопрос, находятся ли крупнейшие города в России в авангарде снижения смертности в ней, а также оценить динамику и размер разрывов в ожидаемой продолжительности жизни между ними и их областями.

\section{ДАННЫЕ И МЕТОДЫ}

Объектом изучения в работе являются города России, в которых численность постоянного населения превышает один миллион человек. Работа основана на данных государственной статистики России за 1989-2016 гг. о распределении умерших по полу и пятилетним возрастным группам $(0 ; 1-4 ; \ldots 85+)$ для отобранных российских городов, чье население на 1 января 2017 г. превышало один миллион человек. Численность постоянного населения по городам в их административных границах на 1 января 1989-2017 гг. взята по данным 
Росстата. Для расчета ожидаемой продолжительности жизни при рождении в городахмиллионниках и в остальной части регионов, административными центрами которых являются города-миллионники, были построены краткие таблицы смертности. Стоит сказать, что, по мнению многих демографов, качество проведения переписей 2002 и 2010 г. в Москве вызывает большие опасения [Андреев 2012; Мкртчян 2012]. Особенно остро стоит проблема завышения численности москвичей в самых старших возрастных группах, что приводит к искажению в большую сторону московских показателей ожидаемой продолжительности жизни при рождении [Папанова и др. 2017]. Следуя работе Папановой с соавторами, для получения более реалистичных оценок ожидаемой продолжительности жизни при рождении мы скорректировали рассчитанные для Москвы таблицы смертности с учетом методологии, используемой в Human Life Table Database. Суть коррекции заключается в модификации а85+ путем подбора такого значения $\mathrm{a}_{85}$ $\left(=1 / \mathrm{m}_{85+}\right)$, которое эмпирически (на основе сравнения всего массива таблиц смертности, построенных для стран с качественной статистикой) соответствовало бы наблюдаемому значению е 0 [Shkolnikov V.M. et al. 2017: Appendix 1].

На 1 января 2017 г. в России было 15 городов с постоянной численностью населения свыше одного миллиона человек ${ }^{1}$. Принимая во внимание существенные различия в численности населения между Москвой и Санкт-Петербургом, с одной стороны, и другими крупнейшими населенными пунктами России, с другой (совокупное население двух столичных городов в последние годы превышает суммарное население всех остальных российских городов-миллионников), представляется обоснованным отдельно рассматривать Москву и Санкт-Петербург и вместе оставшиеся города-миллионники. Для этого нами была введена новая категория - суммарный город - совокупность нестоличных городов-миллионников (т.е. всех российских городов-миллионников, кроме Москвы и Санкт-Петербурга), все показатели для которого рассчитаны путем сложения чисел умерших и численности населения включенных в него городов.

Все российские города-миллионники, за исключением Москвы и Санкт-Петербурга, являются также и административными центрами различных субъектов федерации (областей, республик и краев), концентрируя в себе значительную часть населения и экономического потенциала соответствующих регионов. Чтобы ответить на вопрос, каков уровень смертности в этих регионах за пределами региональных центров, нами были рассчитаны значения ожидаемой продолжительности жизни при рождении для этих регионов без учета населения, проживающего в центрах регионов (городах-миллионниках) и смертей, в них зарегистрированных. По аналогии с суммарным городом для удобства сравнения была сконструирована категория суммарный регион. Кроме того, нами была рассчитана ожидаемая продолжительность жизни для остальной территории России, которая не включала бы население городов-миллионников, а также население

\footnotetext{
${ }^{1}$ Количество и состав городов-миллионников в России в 1989-2016 гг. претерпевали определенные изменения (Приложение 1). Для сопоставимости во времени в каждый год мы будем рассматривать все пятнадцать городов, даже если не во всех из них в этот период численность населения превышала один миллион человек.
} 
Северокавказского федерального округа $(\text { СКФО })^{2}$, т.е. по сути - для России без «мегаполисов».

Основное ограничение данной работы проистекает из определенного несовершенства методик сбора и обработки официальных данных российской статистикой, которое может привести к проблеме смещения числителя и знаменателя при расчете коэффициентов смертности и, следовательно, при построении таблиц смертности. Так, смерть человека может быть зарегистрирована не только по месту его юридического проживания (где он числится в знаменателе - постоянном населении), но и по месту его смерти. Это особенно актуально для крупных городов как центров притяжения мигрантов, не учтенных статистикой, а также пациентов, приезжающих на лечение в крупные города административные центры своих регионов или в Москву и умирающих там [Демографическая ситуация... 2006: 264].

Еще острее стоит «проблема знаменателя». Во-первых, межпереписные оценки населения для всех городов-миллионников, кроме Москвы и Санкт-Петербурга, не пересчитываются от результатов последней переписи, что хорошо видно на графике численности постоянного населения суммарного города за 1989-2017 гг. (Приложение 2). Здесь же можно наблюдать и влияние изменений практики статистического учета на излете советского периода: население Самары, Перми, Нижнего Новгорода, Красноярска, Челябинска, Екатеринбурга на 1 января 1989 г. включало население ЗАТО (суммарно примерно 200 тыс. человек), начиная с 01.01.1990 население ЗАТО исключено из оценок Росстатом постоянного населения этих городов. Другой аспект - качество проведение в России переписей 2002 и 2010 г., особенно в Москве и республиках Северного Кавказа [Андреев 2012] (во многом именно поэтому последние были полостью исключены из нашего исследования); происходит двойной учет одних групп населения (студентов, мужчин призывного возраста) и недоучет других (иностранцев, трудовых мигрантов), злоупотребление административными базами данных, которые не всегда отображают актуальную ситуацию (в первую очередь, они недоучитывают эмиграцию), что приводит в том числе к проблеме «бессмертных пожилых», которую можно отчетливо наблюдать в Москве и Санкт-Петербурге (Приложение 3). Вместе с тем внесенные в ответ на данные ограничения коррективы в методологию исследования несколько снизили влияние этих проблем на полученные результаты.

\section{РеЗУЛЬтаты}

На рисунке 1 со второй половины 1990-х годов можно наблюдать значительную дивергенцию ожидаемой продолжительности жизни при рождении между Москвой и Санкт-Петербургом (и в меньшей степени другими городами-миллионниками), с одной стороны, и остальной территорией России - с другой. Переломной точкой стал 1994 год른 после которого смертность в крупнейших городах страны (и, особенно, в двух столицах) стала снижаться опережающими темпами. Рост смертности в начале 2000-х годов также

\footnotetext{
${ }^{2}$ СКФО не включен в силу ряда причин, касающихся сомнений в качестве данных в округе.

${ }^{3}$ Год с самой низкой ОПЖ при рождении в России как минимум за последние полвека.
} 
шел интенсивнее на остальной территории России ${ }^{4}$, что только усилило разрыв в продолжительности жизни между «периферией» и «центром», представленным в нашем исследовании крупнейшими городами с численностью населения свыше одного миллиона человек. Разрыв между максимальным и минимальным значением ожидаемой продолжительности жизни в этот период (1994-2005 гг.) вырос с 1,36 года для мужчин и 1,05 года для женщин до 9,18 (8,98 по скорректированным данным) и 4,67 $(4,63)$ года соответственно (рисунок 1). Особенно значителен отрыв Москвы как от остальной территории страны, так и от других городов-миллионников, включая Санкт-Петербург, смертность в котором в свою очередь остается ниже, чем во всех других рассматриваемых городах. Подъем смертности, имевший место в России в первой половине 2000-х годов, в меньшей степени затронул крупнейшие города страны (как уже отмечалось выше) и почти не затронул Москву, что сильно отличает ее от остальных субъектов РФ ${ }^{5}$.

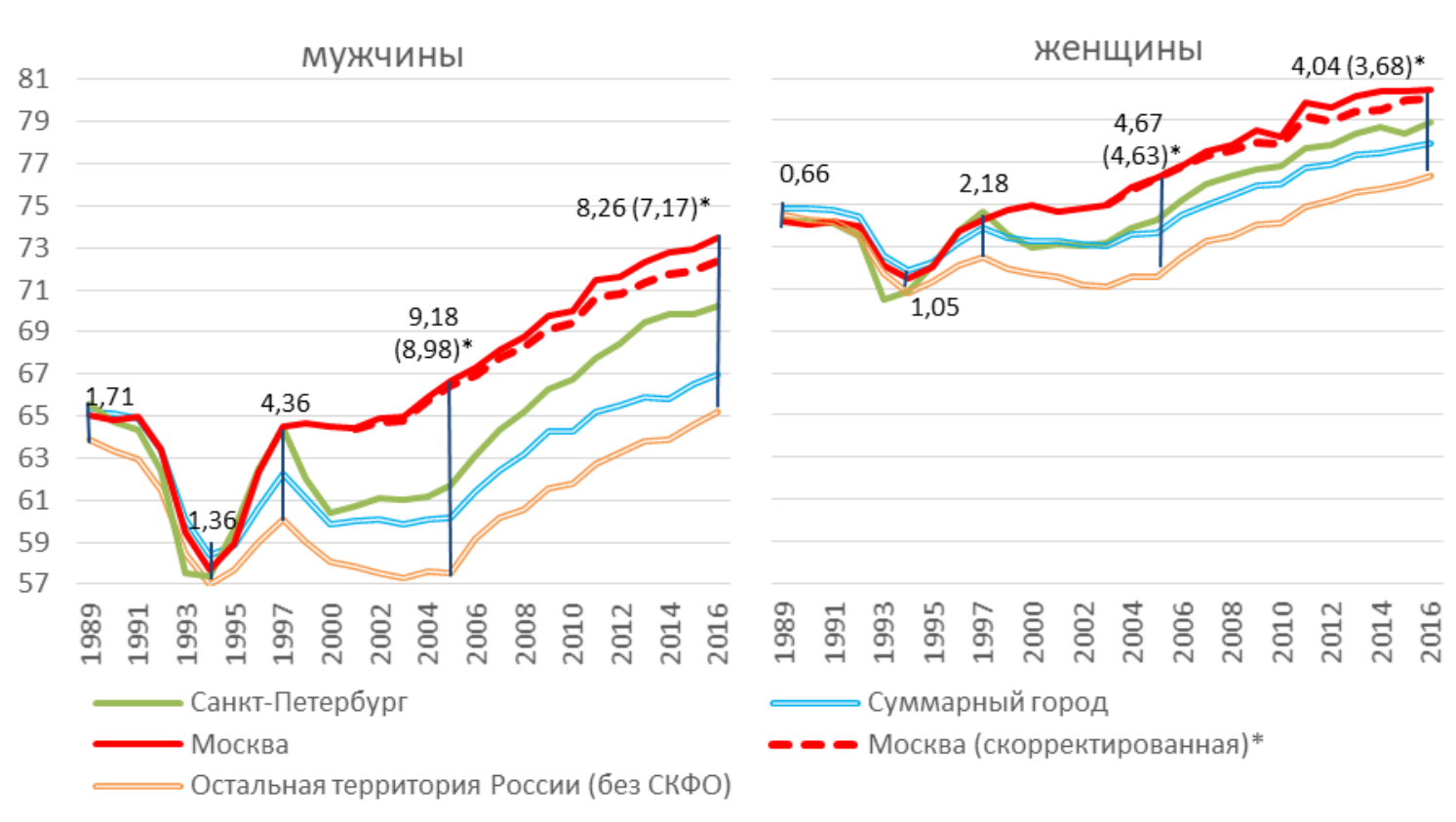

\section{Рисунок 1. Ожидаемая продолжительность жизни при рождении в Москве, Санкт- Петербурге, суммарном городе и на остальной территории России (без СКФО), 1989-2016, годы}

Примечание: Вертикальные линии на графике показывают размах между максимальным и минимальным значением в выбранные годы.

Снижение смертности, начавшееся в России в 2004 г., отличается от предыдущих кратковременных периодов ее сокращения своей рекордной (для периода с 1965 г.) длительностью [Shkolnikov et al. 2013]. Однако рост ожидаемой продолжительности жизни, наблюдавшийся в этот период во всех регионах страны, не сопровождался каким-либо значительным сокращением уровня неравенства в смертности между «столицами» (Москвой и Санкт-Петербургом) и остальной территорией России. Вместе с тем самые

\footnotetext{
4 Тогда как рост смертности в начале 1990-х годов был сильнее выражен в крупных городах [Shkolnikov et al 1998: 1995-2011].

${ }^{5}$ Помимо Москвы, минимальный рост смертности отмечался в северокавказских республиках, а также в «нефтегазовых» округах (ХМАО, ЯНАО).
} 
высокие темпы увеличения продолжительности жизни в 2004-2016 гг. отмечались именно в Санкт-Петербурге, что позволило ему существенно оторваться от суммарного города и сократить отставание от Москвы. Кроме того, обращает на себя внимание слабая (относительно как столиц, так и остальной территории страны) динамика ожидаемой продолжительности жизни мужского населения в суммарном городе в 2010-е годы. В большинстве городов-миллионников в этот период перестает снижаться или даже увеличивается смертность от некоторых причин смерти, обусловленных злоупотреблением алкоголем (отравления, циррозы), однако схожие процессы происходят и в России в целом. Что действительно отличает ситуацию в суммарном городе от остальной территории страны в этот период, так это намного более высокий уровень смертности от болезни, вызванной ВИЧ [Щур 2018: 109].

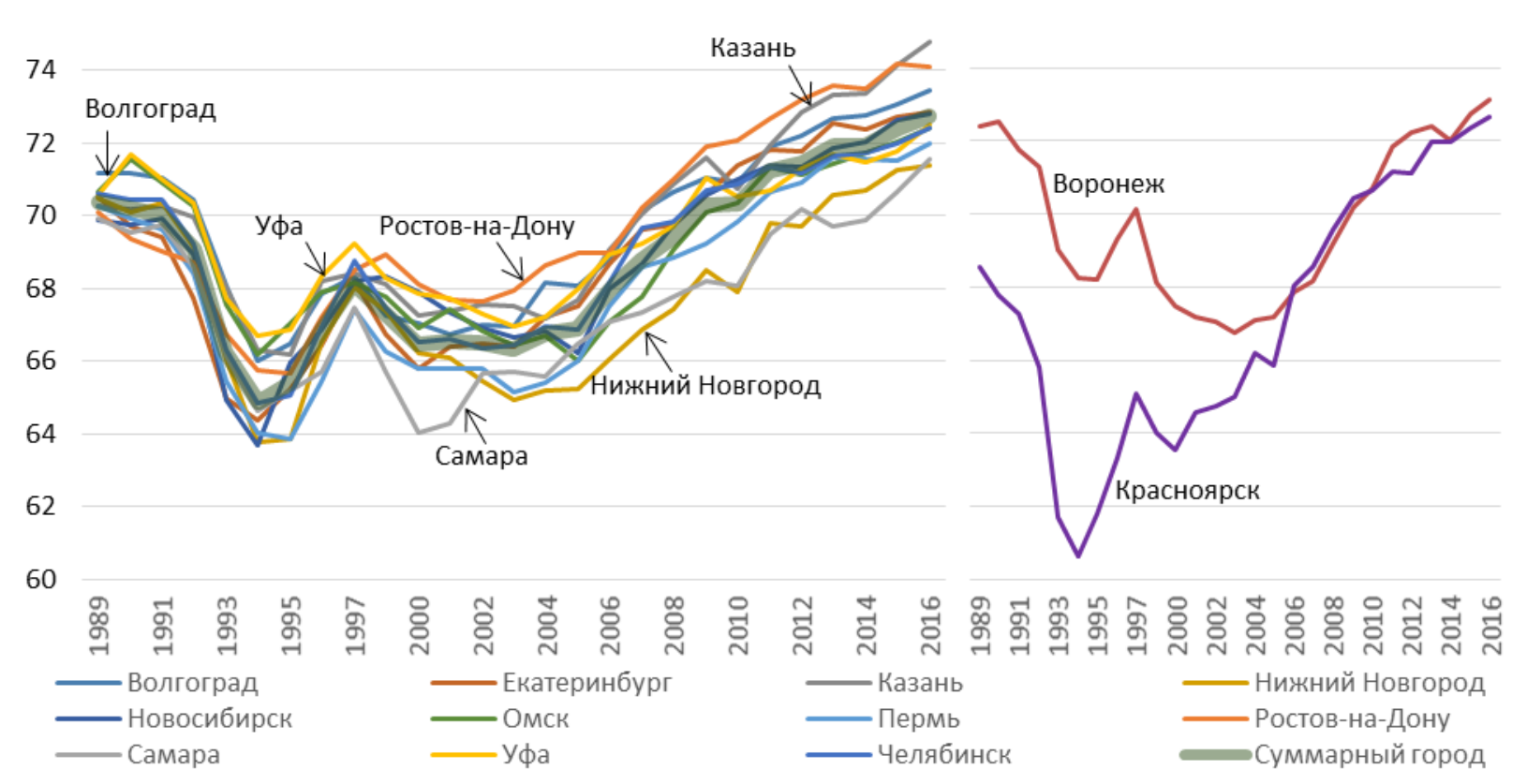

Рисунок 2. Ожидаемая продолжительность жизни при рождении в городахмиллионниках (кроме Москвы и Санкт-Петербурга) и суммарном городе, 1989-2016, годы ${ }^{6}$

На рисунке 2 представлена динамика ожидаемой продолжительности жизни при рождении в городах-миллионниках за исключением Москвы и Санкт-Петербурга; из него следует, что в исследуемый период для городов-миллионников были характерны те же колебания, что и для России в целом. Тем не менее размах этих колебаний был неодинаков для разных городов, что предопределило увеличение разрыва между максимальным и минимальным значением продолжительности жизни с 1,26 года в 1989 г. до 3,37 года в 2016 г. (величина стандартного отклонения для 11 городов-миллионников ${ }^{7}$ за этот же период выросла с 0,37 года до 1,02 года - Приложение 5). В 1990-е годы самая высокая продолжительность жизни отмечалась поочередно в Волгограде, Уфе и Омске, самая низкая - в Новосибирске, Екатеринбурге, Перми. В 2000-е годы картина поменялась: сложилась группа «аутсайдеров» (Самара и Нижний Новгород), существенно отстающая от

\footnotetext{
${ }^{6}$ См. Приложение 4.

${ }^{7}$ Без Воронежа и Красноярска.
} 
других городов-миллионников, и дуэт лидеров (Казань и Ростов-на-Дону), где уровень смертности значительно ниже общероссийского.

Традиционные факторы, влияющие на уровень смертности, такие как уровень образования населения или уровень социально-экономического развития территории, как будет показано ниже в разделе «Дискуссия», полностью не объясняют различия в ожидаемой продолжительности жизни между российскими городами-миллионниками. Обнаружить какую-либо связь между размером города (численностью его населения) или географическим положением (принадлежностью к тому или иному российскому макрорегиону) и величиной продолжительности жизни также не удалось. Если обратиться к группе городов, в которых в настоящее время фиксируется пониженный (относительно суммарного города) уровень смертности, то их объединяют либо более благоприятные климатически условия (Волгоград, Воронеж, Ростов-на-Дону), либо эти города - среди лидеров по развитию третичного сектора экономики с соответствующей структурой занятости ${ }^{8}$ (Екатеринбург, Новосибирск, отчасти Казань, Ростов-на-Дону).

Отдельно хотелось бы остановиться на сравнении Красноярска и Воронежа. Оба эти города до начала 2010-х годов не были миллионниками, при этом в 1990-е годы по уровню продолжительности жизни они располагались на противоположных полюсах, значительно отличаясь в лучшую (Воронеж) и худшую (Красноярск) сторону от всех других исследуемых городов. В 1994 г. Красноярск по величине ожидаемой продолжительности жизни отставал от Воронежа почти на 8 лет. Но уже к 2006 г. Красноярск по этому показателю обгоняет Воронеж; с тех пор в обоих городах отмечается в целом схожий уровень смертности. Возможное объяснение такого сильного разрыва в продолжительности жизни в начале 1990-х годов и последующего его сокращения до минимума к середине 2000-х годов - различная реакция населения на «шоковую терапию», а также различная глубина и скорость проведения рыночных реформ в «патриархальном» Черноземье, бывшем частью «красного пояса», и в Восточной Сибири (регион нового освоения с большим числом недавних приезжих, оказавшихся особенно уязвимыми к радикальной перестройке социально-экономического строя) [Walberg et al 1998].

На рисунке 3 изображена динамика ожидаемой продолжительности жизни при рождении в городах-миллионниках и в остальных населенных пунктах, подчиненных им регионов, в 1989 и 2016 г. За рассматриваемый период различия в продолжительности жизни между «центрами» и «периферией» значительно выросли во всех исследуемых регионах. Если в 1989 г. ожидаемая продолжительность жизни в суммарном городе была на 0,8 года выше, чем в суммарном регионе, то в 2016 г. разрыв увеличился почти до 2,5 лет. Во всех субъектах федерации, представленных на рисунке 3, включая два «столичных региона» (Приложение 6), продолжительность жизни в административных центрах в 19892016 гг. росла намного более быстрыми темпами, чем в остальных населенных пунктах. В ряде регионов, таких как Свердловская и Челябинская области, ожидаемая

\footnotetext{
${ }^{8}$ Повышена доля занятых умственным трудом («белые воротнички») и понижена доля занятых ручным трудом («синие воротнички»).
} 
продолжительность жизни за пределами региональных центров в 2016 г. все еще не достигала уровня 1989 г.

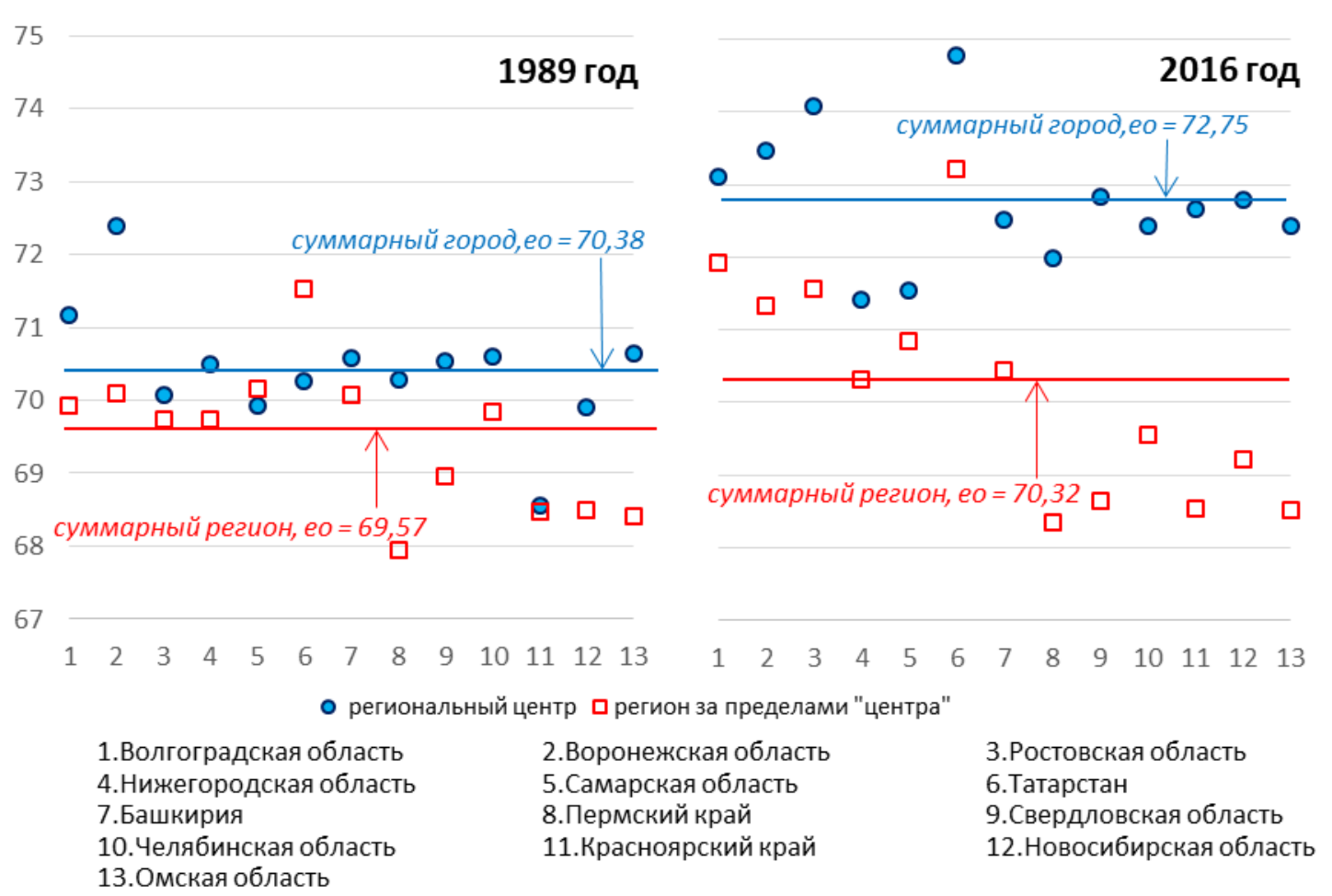

\section{Рисунок 3. Ожидаемая продолжительность жизни при рождении в городах- миллионниках, на остальной территории их областей, в суммарном городе и суммарном регионе в 1989 и 2016 г., годы}

Возможные причины разрыва в продолжительности жизни между городамимиллионниками и окружающими их территориями: различный уровень социальноэкономического развития и различный профессионально-образовательный состав населения, неравенство в доступе к современным медицинским технологиям, селекция в результате миграции. Вместе с тем на размах разрыва в ОПЖ могут влиять и другие факторы, определяемые особенностью поселенческой структуры конкретного региона: степень его урбанизированности, доля населения, проживающего в агломерационном поясе административного центра, наличие других крупных городов-центров. Самые сильные различия в продолжительности жизни между «центром» и «периферией» в 2016 г. наблюдались в регионах Урала (Свердловская, Челябинская область, Пермский край) и Сибири (Новосибирская, Омская область, Красноярский край), минимальная разница, как и в 1989 г., фиксируется в Поволжье (Самарская, Нижегородская область).

\section{Дискуссия}

Ожидаемая продолжительность жизни при рождении в большинстве городов с численностью населения более одного миллиона человек с конца 1990-х годов выше, чем на остальной территории России. При этом ни один другой российский город-миллионник с начала XXI века не демонстрирует такую же динамику и показатели уровня смертности, как Москва, что подтверждает ее уникальное положение на «карте смертности» России. 
Чем же можно объяснить различия в уровне смертности между городами-миллионниками и остальной страной, а также между Москвой и другими крупнейшими российскими городами? Мы сконцентрируем наше внимание на двух факторах: уровне экономического развития (как прокси-показателе уровня жизни) и образовательном составе населения.

Связь между ожидаемой продолжительностью жизни при рождении и уровнем экономического развития, выраженным через объем валового внутреннего продукта (ВВП) на душу населения, на уровне отдельных территорий (как правило, государств) описывает так называемая кривая Престона, показывающая, что существует прямая зависимость между эти двумя показателями [Preston 2007]. Однако Россия как на уровне всей страны (ожидаемая продолжительность жизни при рождении, исходя из величины ВВП на душу населения, должна быть существенно выше наблюдаемой), так и на уровне регионов (какаялибо связь между долголетием и экономическими показателями в нашей стране отсутствует) выбивается из этой закономерности [Андреев, Школьников 2018]. Вместе с тем наша страна характеризуется сильной поляризацией экономического пространства, в том числе на субрегиональном уровне. Так, в тринадцати нестоличных городахмиллионниках в 2015 г. проживало $37 \%$ суммарного населения регионов, административными центрами которых они являются, при этом в них было произведено $48 \%$ совокупного валового регионального продукта (ВРП) этих регионов (Приложение 7). В 2015 г. ВРП на душу населения в одиннадцати из тринадцати рассматриваемых субъектов федерации был выше в центре, чем на остальной территории региона (в 1,4-3,2 раза), лишь в Татарстане (добыча и переработка нефти) и Красноярском крае (Норильский никель, Ванкорское нефтегазовое месторождение) наблюдалась обратная ситуация. В среднем ВРП на душу населения в городах-миллионниках был в 1,6 раза выше, чем в населенных пунктах их областей.

На рисунке 4 (левый график) видно, что в 2015 г. самый высокий ВРП на душу населения, значительно превышающий значения в других городах-миллионниках и на остальной территории России, был зафиксирован в Москве, это же справедливо и для величины ожидаемой продолжительности жизни при рождении. Кроме того, во всех городах-миллионниках валовой городской продукт на душу (ВГП) был выше, чем на остальной территории страны, так же, как и величина продолжительности жизни. Вместе с тем без учета Москвы какая-либо связь на уровне городов-миллионников между величиной валового городского продукта на душу населения и ожидаемой продолжительностью жизни при рождении отсутствовала.

На правом графике (рисунок 4) можно наблюдать, помимо городов-миллионников, ВРП на душу населения и ОПЖ при рождении в регионах, административные центры которых - города-миллионники, но без учета последних, т.е. на остальной территории соответствующих областей (и республик). Диаметр круга на графике прямо пропорционален населению региона. Как и на левом графике, на правом видно, что между ВРП (ВГП) на душу населения и ожидаемой продолжительностью жизни при рождении существует прямая связь, и это при том, что валовой региональный продукт как показатель уровня экономического развития отнюдь не лишен недостатков (так, доля экономики, приходящейся на малый бизнес, который сложнее охватить статистическим наблюдением, как и доля теневой экономики, может сильно различаться между регионами). С другой 
стороны, высокий уровень экономического развития не всегда транслируется в хорошее состояние здоровья населения. Наглядный пример - Красноярский край за пределами региональной столицы, где очень высокий ВРП на душу населения сочетается с очень низкой продолжительностью жизни. Однако в целом нам кажется, что на субрегиональном уровне в России экономическая поляризация (неравенство) между центральными городами и остальной территорией соответствующих областей и вытекающая из этого разница в уровне жизни могут служить одним из объяснений существующего центральнопериферийного разрыва в уровне здоровья (смертности) населения.

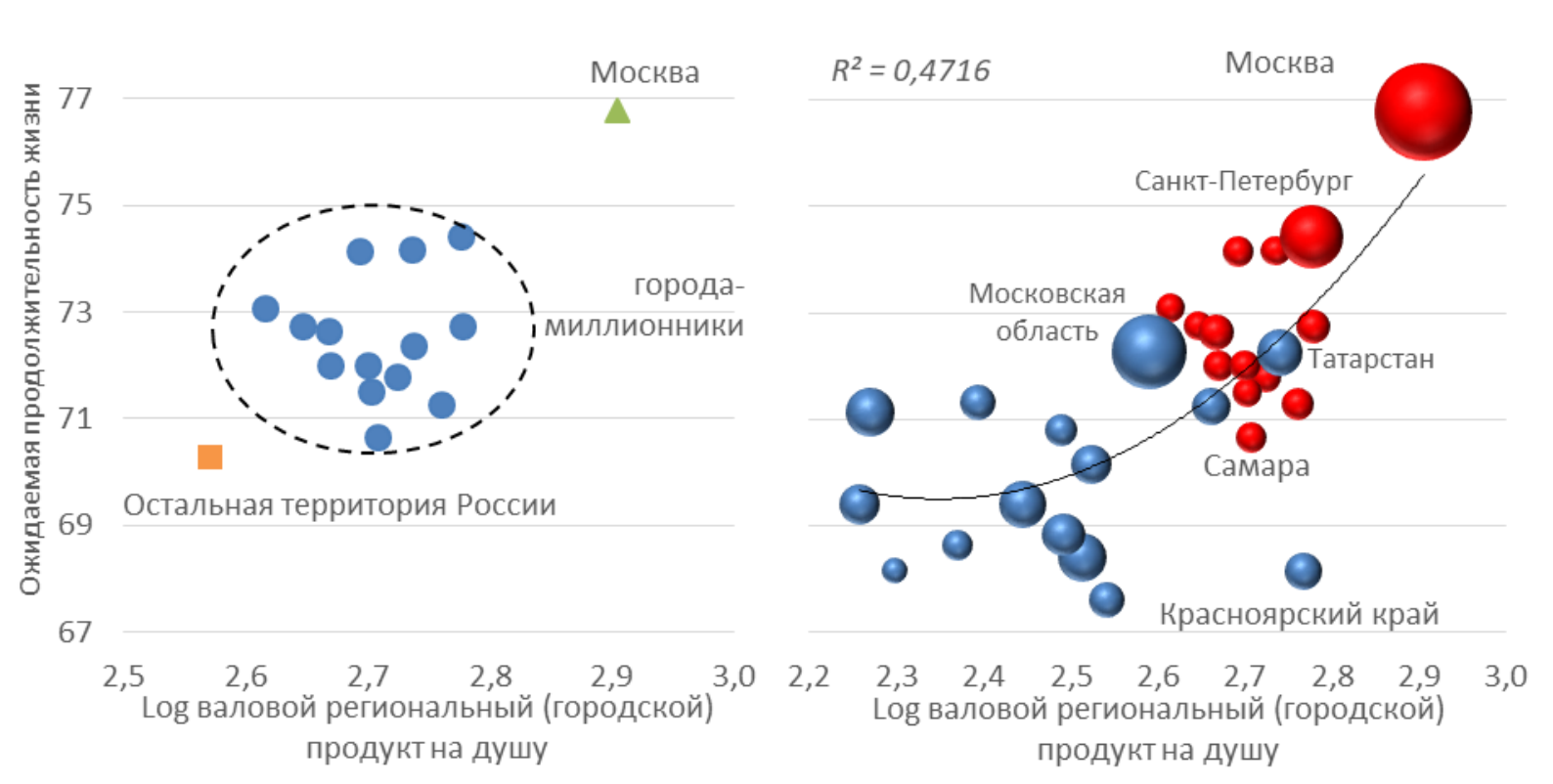

Рисунок 4. Взаимосвязь между ожидаемой продолжительностью жизни при рождении и валовым городским (региональным) продуктом на душу населения (по ППС) в российских городах-миллионниках (красный цвет), на остальной территории их областей (синий цвет) и на остальной территории России, 2015

Благодаря более высокому уровню экономического развития (а значит, и более высокому уровню жизни) почти все города-миллионники в России являются центрами притяжения для внутренних и внешних мигрантов, которые, как правило, в силу селективности (для того чтобы совершить переезд и закрепиться, желательно обладать крепким здоровьем) имеют более низкие показатели смертности, по сравнению как с принимающим («коренным») населением, так и с население тех мест, откуда мигранты происходят [Razum, Zeeb, Rohrmann 2000: 191-192; Marmot, Adelstein, Bulusu 1984: 14551457]. Особенно сильно в России это проявляется на субрегиональном уровне (а в случае Москвы и Санкт-Петербурга - и на межрегиональном), когда наиболее целеустремленные, образованные и, главное, здоровые люди с периферии стремятся переехать в столицы или в областной центр, а не вовлеченными в миграцию остаются менее образованные и амбициозные. Все это приводит к отрицательной селекции по уровню здоровья на периферии и к положительной - в административном центре региона. Это, безусловно, способствует укреплению центрально-периферийного неравенства в смертности в России.

Один из важнейших факторов, влияющих на уровень смертности, - образовательный статус. Многочисленные исследования, в том числе в России, показывают, что люди с более 
высоким уровнем образования живут дольше, чем с более низким [Shkolnikov et al. 2004; Харькова, Никитина, Андреев 2017; Пьянкова, Фаттахов 2017]. Образовательный градиент также отмечается и в младенческой смертности (в зависимости от образовательного статуса матери) [Cochrane, Ohara, Leslie 1980: 95; Кваша 2008]. Учитывая, что почти все городамиллионники в России еще с советского времени являются крупными университетскими центрами (а в своих регионах - крупнейшими и подчас единственными), а большая часть иногородних студентов стремится остаться по месту получения высшего образования (а если и хотят переехать, то в еще более крупный город, как правило, в столицу или за рубеж), то немудрено предположить, что в крупнейших городах страны в сравнении с остальной территорией России высшее образование имеет повышенная доля населения, чем в значительной степени и можно объяснить различия между ними в уровне смертности. Для проверки этой гипотезы мы обратились к данным Всероссийской переписи населения 2010 г., в которой содержался вопрос об уровне образования. Нами была рассчитана стандартизованная (по однолетним возрастным группам, стандарт - возрастной состав населения России по переписи 2010 г.) доля лиц в возрасте старше 30 лет (возраст, после которого образовательный статус человека меняется крайне редко), имеющих высшее образование, для всех городов-миллионников, а также для остальных населенных пунктов областей или республик, административные центры которых - города-миллионники и для остальной территории России, суммарного города и суммарного региона. Не указавшие уровень образования были распределены пропорционально между всеми образовательными группами. Полученные результаты представлены на рисунке 5.

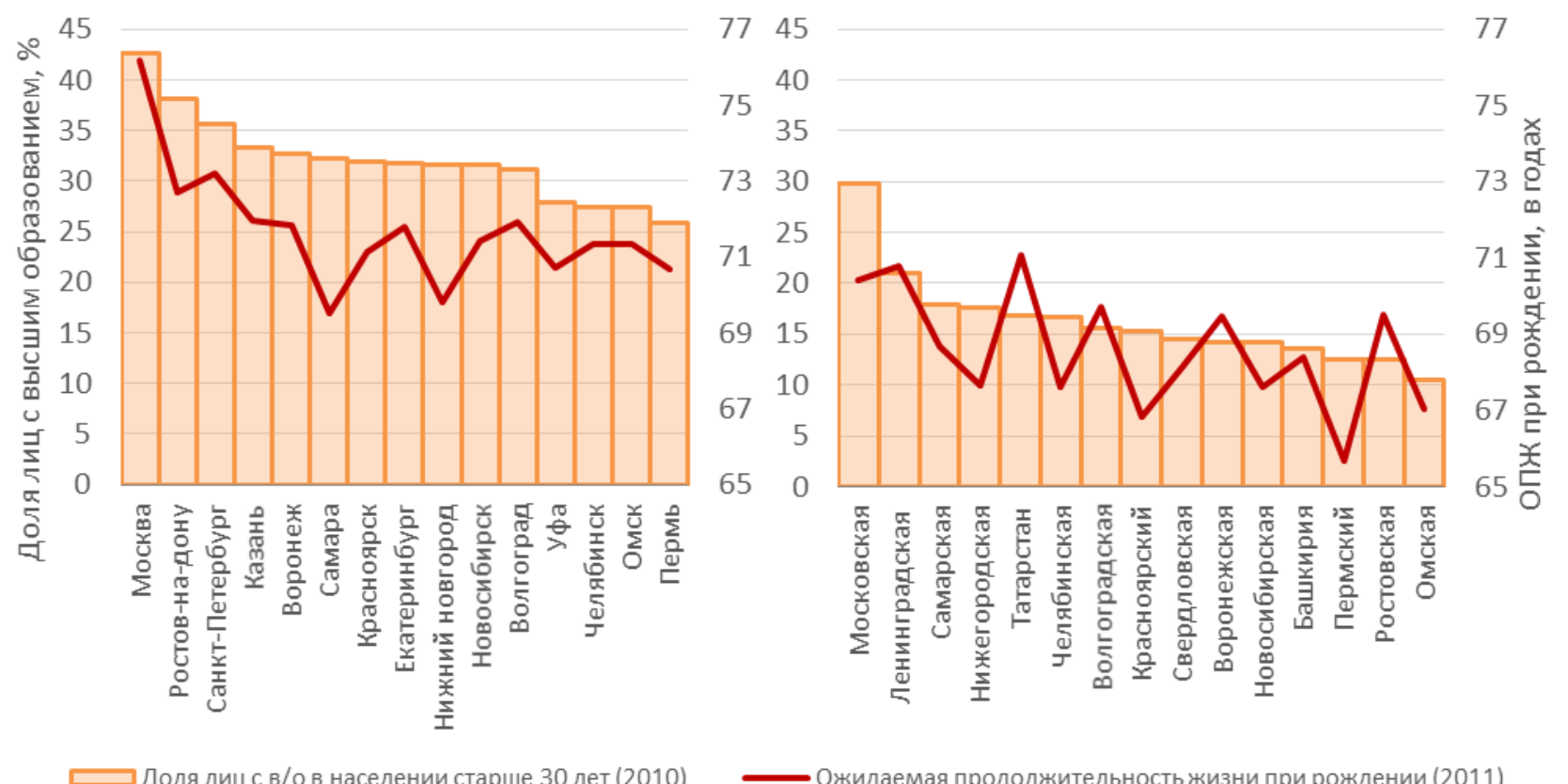

Рисунок 5. Доля лиц в населении старше 30 лет, имеющих высшее образование (левая шкала), и ожидаемая продолжительность жизни при рождении в 2011 г. (правая шкала) в российских городах-миллионниках и на остальной территории соответствующих областей

Действительно, города-миллионники в России отличаются повышенной долей лиц с высшим уровнем образованием (31\% в суммарном городе, который, напомним, не включает 
Москву и Санкт-Петербург, против лишь 15,5\% в суммарном регионе и 19,6\% на остальной территории России). Москва, в свою очередь, как и с ВГП на душу населения, по доле лиц с высшим образованием существенно отличается в лучшую сторону от других городовмиллионников. Интересно, что на втором месте по этому показателю оказался Ростов-наДону, а не Санкт-Петербург, занявший только третье место. В Ростовской же области самый большой разрыв в уровне «образованности» между центром и остальной территорией области. Отметим также, что в населении Московской области доля лиц, окончивших вуз (почти 30\%), выше, чем в четырех из пятнадцати городов-миллионников, при этом в Омской области за пределами Омска лишь один человек из десяти имеет высшее образование.

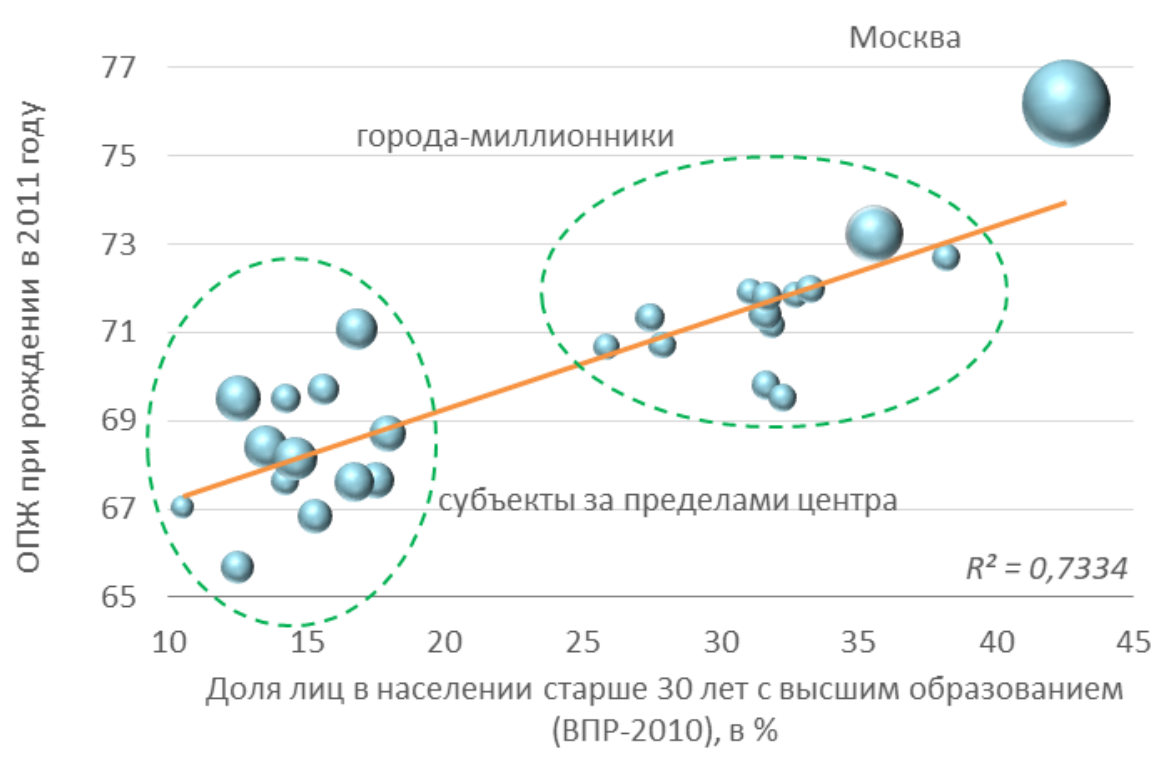

\section{Рисунок 6. Взаимосвязь между ОПЖ при рождении и долей лиц в населении с высшим образованием в российских городах-миллионниках и в их областях за пределами центра}

На рисунке 6 отчетливо проявляются три кластера - Москва, остальные городамиллионники, включая Санкт-Петербург, и их области за пределами центра, - которые заметно отличаются друг от друга как по доле в населении старше 30 лет лиц с высшим образованием, так и по величине ожидаемой продолжительности жизни при рождении. При этом связь между образовательной структурой и смертностью оказывается значительно сильнее, чем между смертностью и уровнем экономического развития. В двух городах - Самаре и Нижнем Новгороде - ожидаемая продолжительность жизни при рождении существенно ниже, чем можно было бы ожидать, исходя из их образовательной структуры (высокой доли лиц с высшим образованием). Возможно, в этих городах по сравнению с другими повышена доля лиц с очень низким уровнем образования, также в случае Самары стоит отметить фактор самой высокой из всех городов-миллионников смертности от ВИЧ, а также от внешних причин смерти [Щур 2018: 109]. Интересно, что если для городов-миллионников уровень образования достаточно сильно коррелирует с величиной ОПЖ при рождении, то для их областей за пределами центра этот фактор не имеет большого значения, намного важнее оказывается географический фактор (юго- 
западный/северо-восточный градиент смертности) и, возможно, еще этнический (в случае Татарстана и в меньшей степени Башкирии).

Объясняя более высокий уровень ожидаемой продолжительности жизни при рождении в городах-миллионниках, не стоит пренебрегать и фактором полноты охвата населения медицинским обслуживанием, особенно современными медицинскими технологиями, которая, в силу плотности (размещения) населения и логистики (инфраструктуры), значительно выше в крупнейших агломерациях, нежели за их пределами. Как пример, если в городах-миллионниках все население живет в часовой транспортной доступности от ЧКВ-центров ${ }^{9}$, то для России в целом этот показатель составляет лишь 45\% [Timonin et al. 2018]. Представляется, что географическое неравенство в уровне доступности современной медицины - это именно то, на что легче всего повлиять правительственным акторам, в то время как другие (структурные) факторы, такие как различие в уровне экономического развития или в образовательной структуре, а также центрально-периферийное направление миграционных потоков, имеют сильный инерционный характер, и их влияние едва ли вообще может быть полностью устранено.

\section{ЗАКЛЮЧЕНИЕ}

За последние десятилетия, прошедшие после распада Советского Союза, уровень неравенства в смертности между российскими городами-миллионниками и остальной территорией России существенно вырос. Отдельно стоит выделить Москву, которая с 2000-х годов по уровню ожидаемой продолжительность жизни при рождении начинает значительно опережать другие российские города-миллионники. Санкт-Петербург занимает промежуточное положение между столицей и «провинциальными» миллионниками, среди которых, в свою очередь, в 2000-е годы выделяются как группа лидеров (Казань и Ростов-на-Дону), так и группа «аутсайдеров» (Нижний Новгород и Самара). Дифференциация городов-миллионников по уровню ожидаемой продолжительности жизни не определяется уровнем их экономического развития (выраженным через валовой городской продукт на душу населения), размером (численностью населения) или географическими координатами, однако можно увидеть некую связь между образовательным составном населения города (долей лиц старше 30 лет, имеющих высшее образование) и продолжительностью жизни в нем. Отрыв городовмиллионников по уровню ОПЖ от «своих» областей не только значительно увеличился в 1989-2016 гг. (в среднем, почти на 2 года), но и, как правило, превышает размер их отрыва от остальной территории страны, т.е. центрально-периферийное неравенство в смертности в России сильнее выражено именно на субрегиональном уровне. Интересно, что югозападный/северо-восточный градиент смертности, слабо работающий на уровне городовмиллионников, хорошо предсказывает различия в продолжительности жизни в их областях за пределами «центров». Таким образом, максимальный уровень центральнопериферийного неравенства в смертности наблюдается в регионах Урала и Сибири, где

\footnotetext{
9 ЧКВ - чрескожное коронарное вмешательство (по-другому, стентирование) - наиболее эффективный способ лечения ишемической болезни сердца.
} 
очень низкая продолжительность жизни за пределами региональных столиц, в то время как в рассматриваемых регионах европейской части России разница между «центрами» и «периферией» существенно меньше (за исключением столичного московского региона). Основная причина центрально-периферийного неравенства в смертности в России, как нам кажется, - это чрезмерная централизация как на страновом уровне, так и на уровне отдельных регионов, приводящая к концентрации в региональных центрах большей части человеческого капитала всего возглавляемого ими региона, а в Москве - человеческого капитала всей страны.

\section{БЛАГОДАРНОСТИ}

Автор выражает благодарность Е.М. Андрееву, С.А. Тимонину, Т.Л. Харьковой и B.M. Школьникову за ценные советы и помощь в подготовке данной статьи.

\section{ЛИТЕРАТУРА}

Андреев Е.М. (1979). Продолжительность жизни в СССР: дифференциальный анализ // Продолжительность жизни: анализ и моделирование. М.: Статистика: 7-31.

Андреев Е.М. (2012). О точности результатов российских переписей населения и степени доверия к разным источникам информации // Вопросы статистики. 11: 21-35.

Андреев Е.М., В.М. Школьников (2018). Связь между уровнями смертности и экономического развития в России и ее регионах // Демографическое обозрение. 5(1): $6-24$.

Андреев Е.М., Е.А. Кваша, Т.Л. Харькова (2006). Особые точки на карте смертности // Население России 2003-2004. Одиннадцатый-двенадцатый ежегодный демографический доклад / Отв. ред. А.Г. Вишневский. М.: 298-305.

Андреев Е.М., Е.А. Кваша, Т.Л. Харькова (2016). Смертность в Москве и других мегаполисах мира: сходства и различия // Демографическое обозрение. 3(3): 39-79.

Вишневский А.Г., Школьников В.М. (1997). Смертность в России: главные группы риска и приоритеты действия. Научные доклады Московского Центра Карнеги, вып. 19. М: Московский Центр Карнеги. 84 с.

Вишневский А.Г. (2014). Смертность в России: несостоявшаяся вторая эпидемиологическая революция // Демографическое обозрение. 1(4): 5-40.

Демографическая ситуация в Москве и тенденции ее развития (2006) / Под ред. Л.Л. Рыбаковского. М.: ЦСП. 264 с.

Зубаревич Н.В. (2010). Города как центры модернизации экономики и человеческого капитала // Общественные науки и современность. 5: 5-19.

Кваша Е.А. (2008). Дифференциация младенческой смертности по уровню образования матери в регионах России в конце 80-х - середине 90-х годов 20 века // Демоскоп Weekly. 331-332. URL: http://www.demoscope.ru/weekly/2008/0331/analit06.php (дата обращения: 04.11.2018). 
Кваша Е.А., Т.Л. Харькова (2009). Россияне и москвичи не равны перед лицом смерти // Демоскоп Weekly. 369-370. URL: http://demoscope.ru/weekly/2009/0369/tema01.php (дата обращения: 04.11.2018).

Мкртчян Н.В. (2012). Проблемы учета населения отдельных возрастных групп в ходе переписи населения 2010 г.: причины отклонений полученных данных от ожидаемых // Демографические аспекты социально-экономического развития. Вып. 22. / Под ред. М.Б. Денисенко. М.: МАКС Пресс: 197-214.

Неравенство и смертность в России (2000) / Под ред. В.М. Школьникова, Е.М. Андреева, Т.М. Малевой. М.: Сигналъ. 123 с.

Папанова Е.К., В.М. Школьников, Е.М. Андреев, С.А. Тимонин (2017). Высокая продолжительность жизни москвичей после 80 лет - реальность или статистический артефакт? // Успехи геронтологии. 6: 826-835.

Пьянкова А.И., Т.А. Фаттахов (2017). Смертность по уровню образования в России // Экономический журнал ВШЭ. 21(4): 623-647.

Семенова В.Г. (2005). Обратный эпидемиологический переход в России. М. 235 с.

Харькова Т.Л., С.Ю. Никитина, Е.М. Андреев (2017). Зависимость продолжительности жизни от уровня образования в России // Вопросы статистики. 8: 61-68.

Шкаратан О.И. (2009). Социально-экономическое неравенство и его воспроизводство в современной России. М.: Олма Медиа Групп. 556 с.

Школьников В.М. (1987). Географические факторы продолжительности жизни // Известия АН СССР. Серия Географическая. 3(12): 35-44.

Щур А. (2018). Тенденции смертности в российских городах с численностью населения свыше одного миллиона человек (1989-2016 гг.): маг. дис-я. М.: НИУ ВШЭ.

Andreev E., V.M. Shkolnikov, T. Valkonen, A. Begun (2001). Measuring inter-group inequalities in length of life // Genus. 57 (3-4): 33-62.

Cochrane SH., DJ. Ohara, J. Leslie (1980). The effects of education on health. Washington, D.C., World Bank. 95 p. (World Bank Staff Working Paper №405.)

Eberstadt N. (1981). The health crisis in the USSR // New York Review Books: 23-21. (Reprinted Int J Epedemiol 2006; 35:1384-94.)

Grigoriev P., F. Meslé, V.M. Shkolnikov, E. Andreev, A. Fihel, M. Pechholdova et al. (2014). The recent mortality decline in Russia: Beginning of the cardiovascular revolution? // Population and Development Review. 40 (1): 107-129.

Grigoriev P., G. Doblhammer-Reiter, V.M. Shkolnikov (2013). Trends, patterns, and determinants of regional mortality in Belarus, 1990-2007 // Population Studies-A Journal of Demography. 67: 61-81.

Kalediene R., J. Petrauskiene (2000). Regional life expectancy patterns in Lithuania // European Journal of Public Health. 10(2):101-104.

Kalediene R., J. Petrauskiene (2004). Socio-economic transition, inequality, and mortality in Lithuania // Economics and Human Biology. 2(1):87-95.

Krumins J., D. Jasilionis, L. Mall, V. Stankuniene (2009). Changes of geographical mortality differences in the three Baltic countries during the period of socio-economic transformation. Paper presented at the IUSSP 26th International Population Conference, Marrakech. 
Marmot M.G., A.M. Adelstein, L. Bulusu (1984). Lessons from the study of immigrant mortality // Lancet. 2: 1455-1457.

Preston S.H. (2007). The changing relation between mortality and level of economic development // International Journal of Epidemiology. 36 (3): 484-90.

Razum O., H. Zeeb, S. Rohrmann (2000). The 'healthy migrant effect'-not merely a fallacy of inaccurate denominator figures // International Journal of Epidemiology. 29(1):191-192.

Shkolnikov V.M. et al. (2017). Methodology Note for the Life Table Database (LTDB). URL: http://www.lifetable.de/methodology.pdf (дата обращения: 05.11.2018).

Shkolnikov V.M., A.D. Deev, Ø. Kravdal, T. Valkonen (2004). Educational differentials in male mortality in Russia and northern Europe. A comparison of an epidemiological cohort from Moscow and St. Petersburg with the male populations of Helsinki and Oslo // Demographic research. 10(1): 1-26.

Shkolnikov V.M., E. Andreev, D. Jasilionis, M. Leinsalu, O. Antonova, M. McKee (2006). The changing relation between education and life expectancy in central and eastern Europe in the 1990s // Journal of Epidemiology and Community Health. 60 (10): 875-881.

Shkolnikov V.M., E. Andreev, M. McKee, D.A. Leon (2013). Components and possible determinants of decrease in Russian mortality in 2004-2010 // Demographic Research. 28(32): 917-950.

Shkolnikov V.M., G.A. Cornia, D.A. Leon, F. Meslé (1998). Causes of the Russian mortality crisis: evidence and interpretations // World Development. 26 (11): 1995-2011.

Shkolnikov V.M., S. Vasin (1994). Spatial differences in life expectancy in European Russia in the 1980s. // Demographic trends and patterns in the Soviet Union before 1991 / W. Lutz, S. Scherbov, A. Volkov, eds. London: Routledge: 379-402.

Timonin S., A. Kontsevaya, M. McKee, D.A. Leon (2018). Reducing geographic inequalities in access times for acute treatment of myocardial infarction in a large country: the example of Russia // International Journal of Epidemiology. 47(5): 1594-1602.

Timonin S., I. Danilova, E. Andreev, V.M. Shkolnikov (2017). Recent mortality trend reversal in Russia: are regions following the same tempo? // European Journal of Population. 33(1): 733763.

Vallin J., E. Andreev, F. Meslé, V.M. Shkolnikov (2005). Geographical diversity of cause-ofdeath patterns and trends in Russia // Demographic Research. 12 (13): 323-380.

Vasin, S., C.A. Costello (1997). Spatial, age, and cause-of-death patterns of mortality in Russia, 1988-1989 // Premature Death in the New Independent States / J.L. Bobadilla, C.A. Costello, F. Mitcell, eds. Washington, DC: National Academies Press: 66-119.

Walberg P., M. McKee, V.M. Shkolnikov, L. Chenet, D.A. Leon (1998). Economic change, crime and Russian mortality crisis: a regional analysis // British Medical Journal. 317 (7154): $312-318$.

WHO Mortality Database (2017). URL: http://www.who.int/healthinfo/mortality_data/en/ (дата обращения:10.08.2018). 


\title{
CITIES OF OVER A MILLION PEOPLE ON THE MORTALITY MAP OF RUSSIA
}

\section{ALEKSEI SHCHUR}

\begin{abstract}
The problem of excess mortality in Russia has not lost its relevance. The situation is complicated by the high level of spatial inequality in health, which is usually measured at the regional level in our country. This work is one of the first attempts to look at the dynamics and extent of spatial inequality in health in Russia at the sub-regional level, by contrasting the "center/core" (in our case, represented by the largest Russian cities) with the "periphery" (the rest of the country). Cities with a population of over a million people were chosen based on the spatial hierarchy that exists in Russia, according to which the highest level of social and economic development is concentrated in the largest cities. As a rule, a higher level of development of human capital corresponds to lower mortality. Using data provided by Rosstat we calculated life expectancy at birth for Russian cities with a population of over a million people in 1989-2016. The results fully coincided with our expectations: the polarization in the health level between the largest Russian cities and the rest of the country has significantly increased in the last twenty-five years, which is a reflection of those centripetal processes that have been taking place in our country during this period. Russian cities with a population of over a million people are attractive destinations for both internal and external migrants, and thus acquire among other things a much more educated population. Since people with higher education take better care of their health, having a more educated population is undoubtedly an essential advantage of bigger cities over the periphery when it comes to the overall health level. Without solving the structural problems that restrain social and economic development outside the largest agglomerations, convergence in mortality rates between cities with a population of over a million people and the surrounding territories is hardly possible.
\end{abstract}

Key words: life expectancy, spatial inequality in mortality, cities with a population of over a million people, educational level, core and periphery.

Aleksei ShChur (aschur@hse.ru), National Research University Higher School of Economics, Russia.

THE RESEARCH WAS FUNDED UNDER THE STATE SUPPORT PROGRAM OF THE LEADING UNIVERSITIES OF THE RUSSIAN FEDERATION “Russian ACADEMIC EXCELLENCE PROJECT 5-100”.

DATE RECEIVED: AUGUST 2018.

\section{REFERENCES}

Andreev E., V.M. Shkolnikov, T. Valkonen, A. Begun (2001). Measuring inter-group inequalities in length of life // Genus. 57(3-4): 33-62.

Andreev E.M. (1979). Prodolzhitel'nost' zhizni v SSSR: differentsial'nyy analiz [Life expectancy in the USSR: differential analysis] // Prodolzhitel'nost' zhizni: analiz i modelirovanie [Lifespan: Analysis and Modeling]. Moscow: Statistika: 7-31.

Andreev E.M. (2012). O tochnosti rezul'tatov rossiyskikh perepisey naseleniya i stepeni doveriya $\mathrm{k}$ raznym istochnikam informatsii [On the accuracy of the results of Russian population censuses and the level of confidence in different sources of information] // Voprosy statistiki [Issues of Statistics]. 11: 21-35.

Andreev E.M., E.A. Kvasha, T.L. Kharkova (2006). Osobye tochki na karte smertnosti [The special points on the map of mortality] // Naselenie Rossii 2003-2004 [Population of Russia 2003-2004]. Odinnadtsatyy-dvenadtsatyy ezhegodnyy demograficheskiy doklad [Eleventhtwelfth annual demographic report] / A.G. Vishnevsky, ed. Moscow: 298-305. 
Andreev E.M., E.A. Kvasha, T.L. Kharkova (2016). Smertnost' v Moskve i drugikh megapolisakh mira: skhodstva i razlichiya [Mortality in Moscow and other megacities of the world: similarities and differences] // Demograficheskoe obozrenie [Demographic Review]. 3(3): 39-79.

Andreev E.M., V.M. Shkolnikov (2018). Svyaz' mezhdu urovnyami smertnosti i ekonomicheskogo razvitiya v Rossii i ee regionakh [The relationship between mortality and economic development in Russia and its regions] // Demograficheskoe obozrenie [Demographic Review]. 5(1): 6-24.

Cochrane SH., DJ. Ohara, J. Leslie (1980). The effects of education on health. Washington, D.C., World Bank. 95 p. (World Bank Staff Working Paper №405.)

Demograficheskaya situatsiya v Moskve i tendentsii ee razvitiya [The demographic situation in Moscow and its development trends] (2006) / L.L. Rybakovsky, ed. Moscow: TsSP. 264 p.

Eberstadt N. (1981). The health crisis in the USSR // New York Review Books: 23-21. (Reprinted Int J Epedemiol 2006; 35:1384-94.)

Grigoriev P., F. Meslé, V.M. Shkolnikov, E. Andreev, A. Fihel, M. Pechholdova et al. (2014). The recent mortality decline in Russia: Beginning of the cardiovascular revolution? // Population and Development Review. 40(1): 107-129.

Grigoriev P., G. Doblhammer-Reiter, V.M. Shkolnikov (2013). Trends, patterns, and determinants of regional mortality in Belarus, 1990-2007 // Population Studies-A Journal of Demography. 67: 61-81.

Kalediene R., J. Petrauskiene (2000). Regional life expectancy patterns in Lithuania // European Journal of Public Health. 10(2):101-104.

Kalediene R., J. Petrauskiene (2004). Socio-economic transition, inequality, and mortality in Lithuania // Economics and Human Biology. 2(1):87-95.

Kharkova T.L., S.Yu. Nikitina, E.M. Andreev (2017). Zavisimost' prodolzhitel'nosti zhizni ot urovnya obrazovaniya $v$ Rossii [The dependence of life expectancy on the level of education in Russia] // Voprosy statistiki [Issues of Statistics]. 8: 61-68.

Krumins J., D. Jasilionis, L. Mall, V. Stankuniene (2009). Changes of geographical mortality differences in the three Baltic countries during the period of socio-economic transformation. Paper presented at the IUSSP 26th International Population Conference, Marrakech.

Kvasha E.A. (2008). Differentsiatsiya mladencheskoy smertnosti po urovnyu obrazovaniya materi v regionakh Rossii v kontse 80 -kh - seredine 90-kh godov 20 veka [Differentiation of infant mortality by the level of education of the mother in the regions of Russia in the late 80s - mid 90s of the 20th century] // Demoscope Weekly. 331-332.

URL:http://www.demoscope.ru/weekly/2008/0331/analit06.php (accessed: 04.11.2018).

Kvasha E.A., T.L. Kharkova (2009). Rossiyane i moskvichi ne ravny pered litsom smerti [Russians and Muscovites are not equal in the face of death] // Demoscope Weekly. 369-370. URL: http://demoscope.ru/weekly/2009/0369/tema01.php (accessed: 04.11.2018).

Marmot M.G., A.M. Adelstein, L. Bulusu (1984). Lessons from the study of immigrant mortality // Lancet. 2: 1455-1457.

Mkrtchyan N.V. (2012). Problemy ucheta naseleniya otdel'nykh vozrastnykh grupp v khode perepisi naseleniya 2010 g.: prichiny otkloneniy poluchennykh dannykh ot ozhidaemykh [Problems of registration of the population of certain age groups during the 2010 census: reasons for deviations of the data from the expected] // Demograficheskie aspekty sotsial'no- 
ekonomicheskogo razvitiya [Demographic aspects of socio-economic development]. Iss. 22. / M.B. Denisenko, ed. Moscow: MAKS Press: 197-214.

Neravenstvo i smertnost' v Rossii [Inequality and Mortality in Russia] (2000) / V.M. Shkolnikov, E.M. Andreev, T.M. Maleva, eds. Moscow: Signal. 123 p.

Papanova E.K., V.M. Shkolnikov, E.M. Andreev, S.A. Timonin (2017). Vysokaya prodolzhitel'nost' zhizni moskvichey posle 80 let - real'nost' ili statisticheskiy artefakt? [High life expectancy of Muscovites after 80 years - a reality or a statistical artifact?] // Uspekhi gerontologii [Advances in gerontology]. 6: 826-835.

Preston S.H. (2007). The changing relation between mortality and level of economic development // International Journal of Epidemiology. 36 (3): 484-90.

P'yankova A.I., T.A. Fattakhov (2017). Smertnost' po urovnyu obrazovaniya v Rossii [Mortality by level of education in Russia] // Ekonomicheskij zhurnal VSHE [HSE Economic Journal]. 21(4): 623-647.

Razum O., H. Zeeb, S. Rohrmann (2000). The 'healthy migrant effect'-not merely a fallacy of inaccurate denominator figures // International Journal of Epidemiology. 29(1):191-192.

Semenova V.G. (2005). Obratnyy epidemiologicheskiy perekhod v Rossii [Reverse epidemiological transition in Russia] (2005). Moscow. 235 p.

Shchur A. (2018). Tendentsii smertnosti v rossiyskikh gorodakh s chislennost'yu naseleniya svyshe odnogo milliona chelovek (1989-2016 gg.) [Mortality trends in Russian cities with a population of over one million people (1989-2016)]: master thesis. Moscow: NRU HSE.

Shkaratan O.I. (2009). Sotsial'no-ekonomicheskoe neravenstvo i ego vosproizvodstvo v sovremennoy Rossii. [Socio-economic inequality and its reproduction in modern Russia] Moscow: Olma Media Grupp. 556 p.

Shkolnikov V.M. (1987). Geograficheskie faktory prodolzhitel'nosti zhizni [Geographical factors of life expectancy] // Izvestiya AN SSSR. Seriya Geograficheskaya [News of the USSR Academy of Sciences. Geographical series]. 3(12): 35-44.

Shkolnikov V.M., E. Andreev, D. Jdanov, J. Vallin, F. Meslé, C. Boe, J. Wilmoth, S. GellersBarkmann (2017). Methodology note for the Life Table Database (LTDB). URL: http://www.lifetable.de/methodology.pdf (accessed: 05.11.2018).

Shkolnikov V.M., A.D. Deev, Ø. Kravdal, T. Valkonen (2004). Educational differentials in male mortality in Russia and northern Europe. A comparison of an epidemiological cohort from Moscow and St. Petersburg with the male populations of Helsinki and Oslo // Demographic research. 10(1): 1-26.

Shkolnikov V.M., E. Andreev, D. Jasilionis, M. Leinsalu, O. Antonova, M. McKee (2006). The changing relation between education and life expectancy in central and eastern Europe in the 1990s // Journal of Epidemiology and Community Health. 60(10): 875-881.

Shkolnikov V.M., E. Andreev, M. McKee, D.A. Leon (2013). Components and possible determinants of decrease in Russian mortality in 2004-2010 // Demographic Research. 28(32): 917-950.

Shkolnikov V.M., G.A. Cornia, D.A. Leon, F. Meslé (1998). Causes of the Russian mortality crisis: evidence and interpretations // World Development. 26(11): 1995-2011.

Shkolnikov V.M., S. Vasin (1994). Spatial differences in life expectancy in European Russia in the 1980s. // Demographic trends and patterns in the Soviet Union before 1991 / W. Lutz, S. Scherbov, A. Volkov, eds. London: Routledge: 379-402. 
Timonin S., A. Kontsevaya, M. McKee, D.A. Leon (2018). Reducing geographic inequalities in access times for acute treatment of myocardial infarction in a large country: the example of Russia // International Journal of Epidemiology. 47(5): 1594-1602.

Timonin S., I. Danilova, E. Andreev, V.M. Shkolnikov (2017). Recent mortality trend reversal in Russia: are regions following the same tempo? // European Journal of Population. 33(1): 733763.

Vallin J., E. Andreev, F. Meslé, V.M. Shkolnikov (2005). Geographical diversity of cause-ofdeath patterns and trends in Russia // Demographic Research. 12(13): 323-380.

Vasin, S., C.A. Costello (1997). Spatial, age, and cause-of-death patterns of mortality in Russia, 1988-1989 // Premature Death in the New Independent States / J.L. Bobadilla, C.A. Costello, F. Mitcell, eds. Washington, DC: National Academies Press: 66-119.

Vishnevsky A., Shkolnikov V. (1997). Smertnost' v Rossii: glavnye gruppy riska i prioritety deystviya (Mortality in Russia: main risk groups and priorities of action). Nauchnye doklady Moskovskogo Tsentra Karnegi (Scientific reports of the Moscow Carnegie Center), Issue 19. Carnegie Endowment for International Peace: 83 p.

Vishnevsky A. (2015). Mortality in Russia: the second epidemiological revolution that never was // Demographic Review, English selection: 4-33.

Walberg P., M. McKee, V.M. Shkolnikov, L. Chenet, D.A. Leon (1998). Economic change, crime and Russian mortality crisis: a regional analysis // British Medical Journal. 317(7154): 312-318. (accessed: 10.08.2018).

Zubarevich N.V. (2010). Goroda kak tsentry modernizatsii ekonomiki i chelovecheskogo kapitala [Cities as centers of economic modernization and human capital] // Obshchestvennye nauki i sovremennost [Social Sciences and Contemporary World]. 5: 5-19. 


\section{ПРИЛОЖЕНИЯ}

\section{Приложение 1. Среднегодовая численность населения в «нестоличных» российских городах-миллионниках, 1989-2016, тыс. человек}

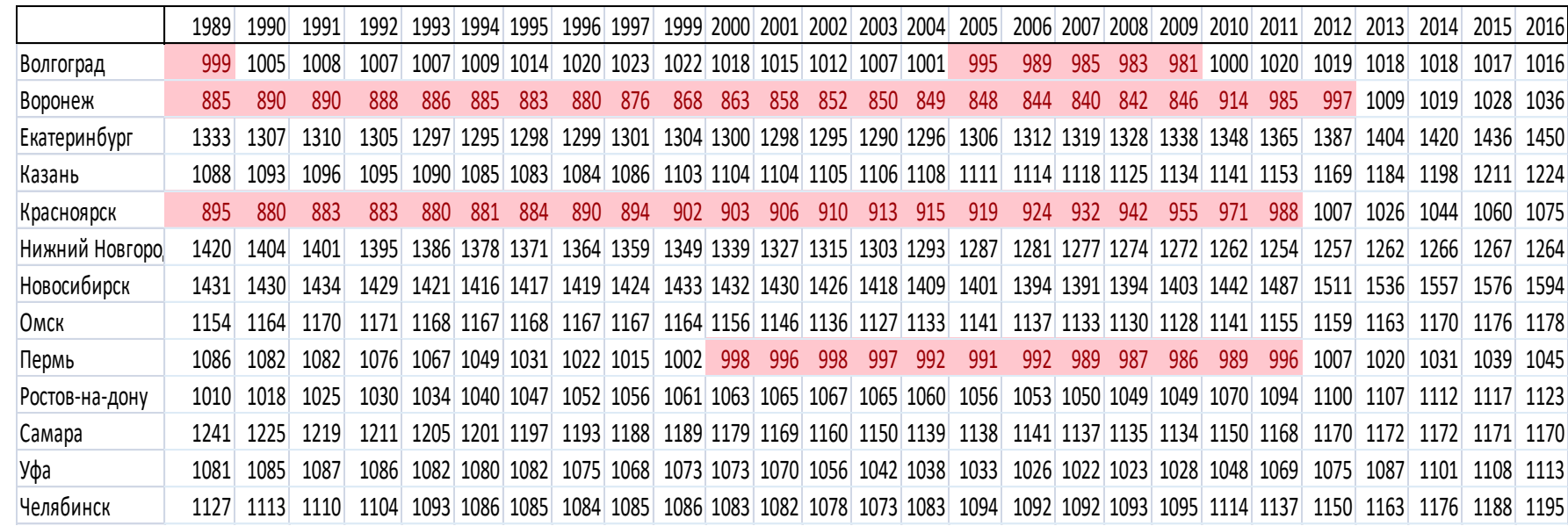

Приложение 2. Численность постоянного населения во всех нестоличных городахмиллионниках (суммарном городе) на 1 января соответствующего года

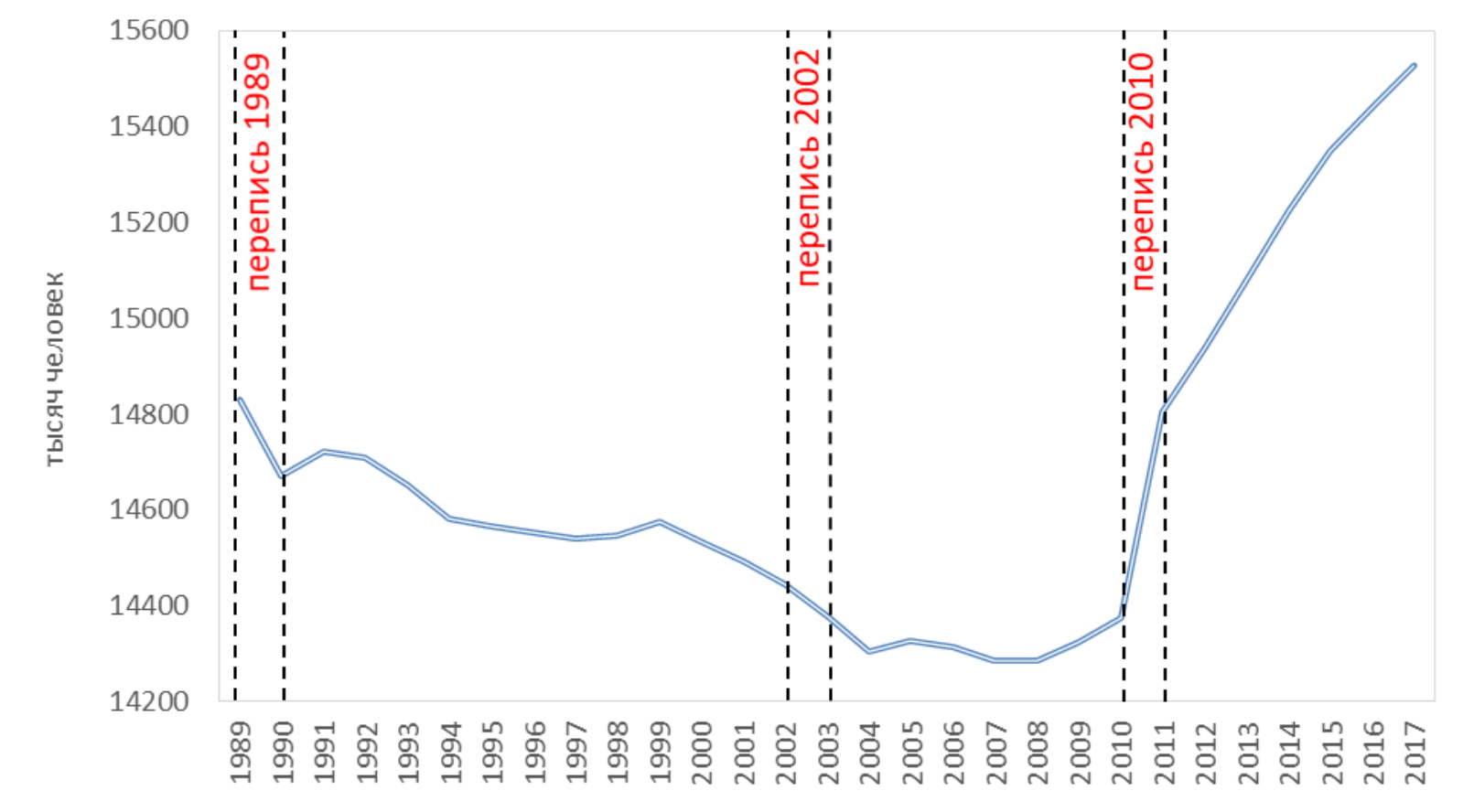


Приложение 3. Коэффициент смертности $\left(\log _{\mathrm{mx}}\right)$ в возрасте старше 80 лет в Москве, Санкт-Петербурге, суммарном городе и Швеции (как стране с одним из самых высоких качеств данных о смертности пожилых)

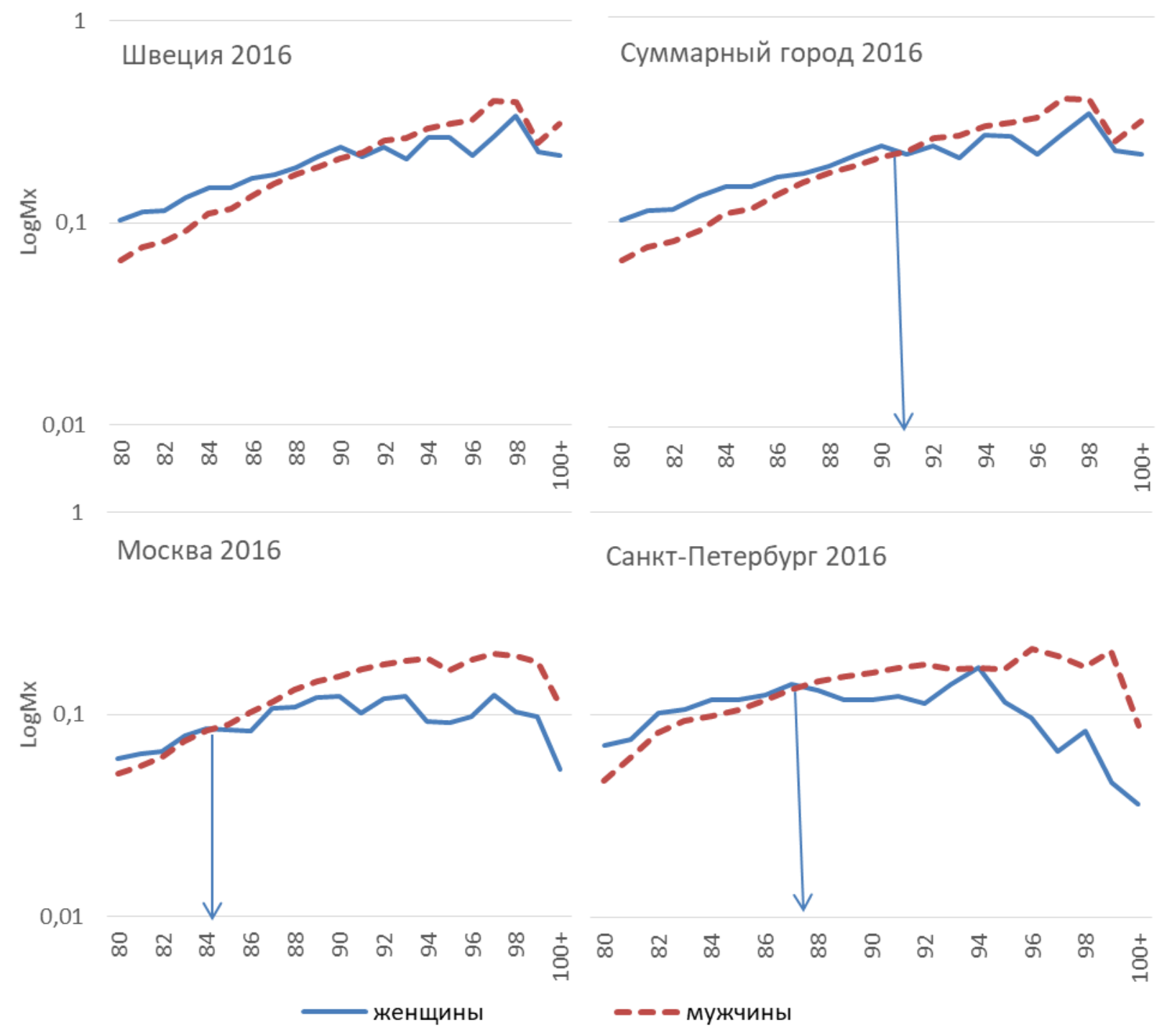




\section{Приложение 4. Ожидаемая продолжительность жизни при рождении в российских городах-миллионниках, 1989-2016}

\section{Мужчинь}

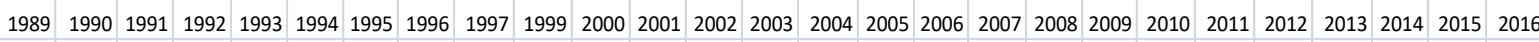

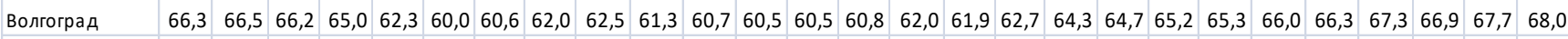

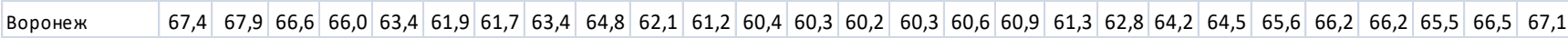

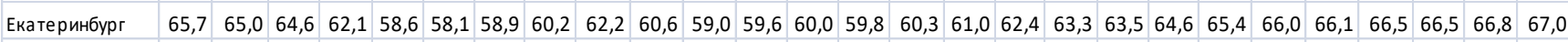

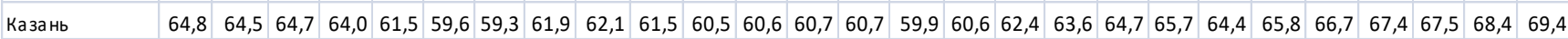

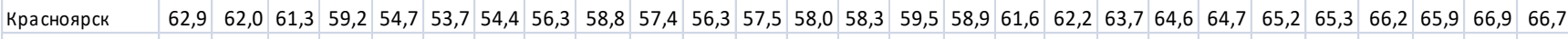

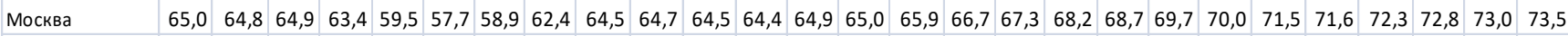

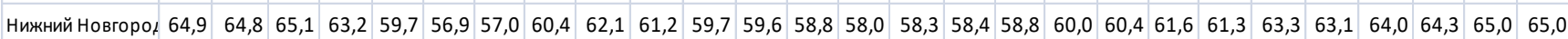

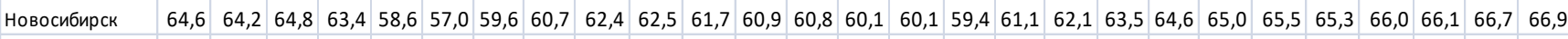

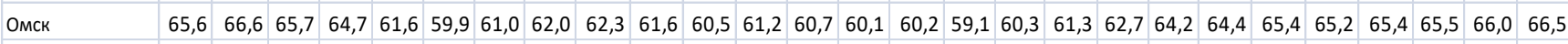

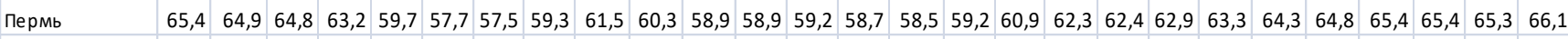

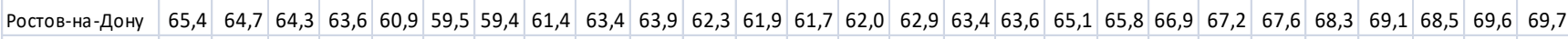

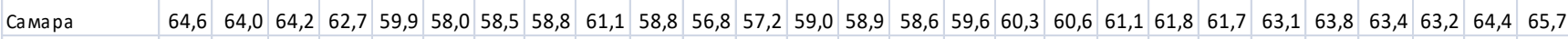
\begin{tabular}{l|l|l|l|l|l|l|l|l|l|l|l|l|l|l|l|l|l|l|l|l|l|l|l|l|l|l|l|l|l} 
Сант-Петербург & 65,6 & 64,7 & 64,3 & 62,4 & 57,5 & 57,4 & 59,6 & 62,5 & 64,4 & 62,0 & 60,4 & 60,7 & 61,1 & 61,0 & 61,1 & 61,7 & 63,1 & 64,3 & 65,2 & 66,3 & 66,8 & 67,8 & 68,4 & 69,4 & 69,8 & 69,8 & 70,3
\end{tabular} $\begin{array}{llllllllllllllllllllllllllllllllll}\text { уфа } & 65,6 & 66,5 & 65,3 & 64,7 & 61,5 & 60,0 & 60,5 & 62,5 & 63,5 & 62,2 & 61,4 & 61,6 & 61,2 & 60,7 & 60,8 & 61,7 & 62,6 & 63,1 & 63,7 & 65,4 & 64,8 & 65,0 & 65,3 & 65,6 & 65,3 & 65,7 & 66,7\end{array}$

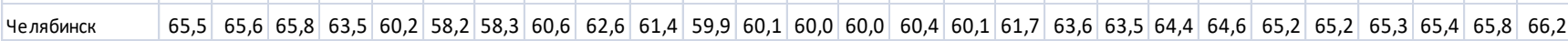

\section{Женцинь}

\begin{tabular}{|c|c|c|c|c|c|c|c|c|c|c|c|c|c|c|c|c|c|c|c|c|c|c|c|c|c|c|c|}
\hline & 889 & 90 & 91 & 92 & 93 & 1 & 5 & 96 & 7 & 99 & 0 & 1 & 2 & 2003 & 04 & 5 & 06 & 2007 & 2008 & 09 & 10 & 2011 & 2012 & 13 & 14 & 15 & 016 \\
\hline & & & &, 5 & & & & & & & & & & & & & & 8 & 4 & 7 & 2 & 4 & 6 & 7,6 & 3,2 & 9 & 8,4 \\
\hline & & & & & & & & & & & & & & & & & & & & & & & & 2 & ,2 & 6 & 8,7 \\
\hline & & 0 & & 1 & & & & & & & & & & & & , & 7 & ,5 & 6 & 0 & 8 & 9 & 8 & ,9 & ,5 & ,9 & 7,9 \\
\hline & & 5,2 & ,2 & 5 & 4 & &, 2 & 3 & & & & & & 4 & 6 & 1,8 & 75,5 & 76,1 & 76,5 & 5,9 & 6 & 77,5 & 8,4 & 3,5 & 8,5 & ,1 & 9,3 \\
\hline oa & & 3,1 & 7 & 4 &, 5 & 6 & 0,3 & 0,9 & 3 & 9 & 3 & , 0 & 8 & 0 & 9, & 72,9 & 74,1 & 74,6 & 74,9 & 75,6 & 76,0 & 76,5 & 76,4 & 7,0 & 7,4 & 1 & 7,9 \\
\hline & & . & 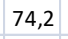 & 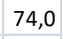 & 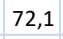 & . & $L$ & 8 & 3 & 7 & 0 & 7 & 8 & 0 & 8 & ,3 & 9 &, 5 & 8 &, 5 & ,2 & 8 & ,6 &, 2 &, 4 & 4 & 30,4 \\
\hline & & 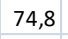 & & & & & & 7 & & & & & & & & & & 7 & & & & 3 & & & 5 & & 7,1 \\
\hline & & & & 0 & & & & 0 & 8 & & & 9 & 1 & 4 & & 4 & 0 & 5,3 & 8 & 2 & 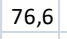 & 5,9 & 1 & 4 & 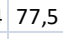 & 8,2 & 78,2 \\
\hline n & , & 5,9 & 6 & 5,5 &, 6 &, 7 & 73,2 & 73,8 & 74,0 & 74,0 & 73,4 & 73,7 & 73,0 & 72,9 & ,3 & 73,3 & 4,0 & 74,2 & 75,2 & 5,6 & 5,9 & 6,8 & 6,6 & 7,1 & 7,5 & 6 & 7,9 \\
\hline ep & 4,4 & 4,4 & 4,0 & 3,4 & 71,2 & 70,7 & 70,6 & 71,7 & 73,2 & 72,0 & 72,6 & 72,5 & 72,3 & 71,8 & 72,5 & 72,9 & 74,0 & 74,5 & 74,9 & 75,1 & 75,9 & 76,4 & 76,4 & 7,1 & 76,9 & 6,9 & 7,1 \\
\hline & 74,2 & 3,5 & ,3 &, 5 & ,5 & 7 & 72,1 & 73,0 & 73,3 & 73,7 & 73,9 & 73,4 & 73,6 & 73,9 & 3 & ,5 & 74,2 & 75,1 & 75,9 & 6 & 6 & 77,4 & 6 & 6 & 3,1 & 2 & 8,0 \\
\hline & & 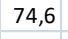 & 8 & 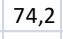 & 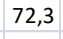 & 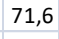 & 3 & 0 & 7 & 2 & . & 1 & 8 & 8 & $\theta$ & 6 & 0 & 1 & 4 & & 3 & 7 & 3 & 7 & 4 & 6,6 & 6,9 \\
\hline & & 4,2 & 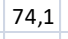 & נו & 7 & 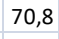 & 7 & 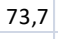 & 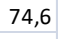 & 73,6 & & L & 0 & 2 & & & 2 & 0 & 3 & & & ,7 & 8 & 4 & 7 & 4 & 78,9 \\
\hline 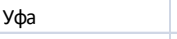 & 74,8 & 6,2 & 2 & 5,5 & 73,8 & 7 & 73,3 & 74,0 & 74,8 & 74,3 & 7 & 3,9 & 73,5 & 73,4 & 73,8 & 4,2 & 5,2 & 75,1 & 5,5 & 5,3 & 9 & 6,0 & 6,9 & 7,4 & 7,2 & 7,4 & 7,8 \\
\hline елябинск & 75,0 & 74,8 & 74,7 & 74,8 & 72,7 & 72,0 & 72,3 & 73,4 & 74,7 & 73,5 & 73,4 & 73,2 & 72,8 & 73,0 & 73,6 & 73,7 & 74,5 & 75,3 & 75,9 & 76,6 & 76,7 & 76,9 & 76,6 & 77,6 & 77,6 & 77,6 & 78,1 \\
\hline
\end{tabular}

\section{Оба пола}

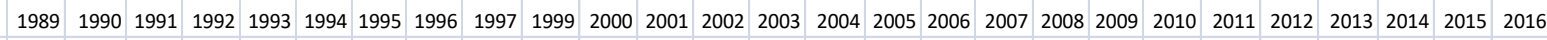

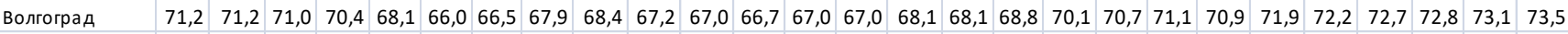
\begin{tabular}{|l|l|l|l|l|l|l|l|l|l|l|l|l|l|l|l|l|l|l|l|l|l|l|l|l|l|l|l|l|l|l|l|l|}
\hline Воронеж & 72,4 & 72,5 & 71,8 & 71,3 & 69,0 & 68,3 & 68,2 & 69,3 & 70,2 & 68,1 & 67,5 & 67,2 & 67,1 & 66,7 & 67,1 & 67,2 & 67,9 & 68,2 & 69,2 & 70,2 & 70,7 & 71,8 & 72,3 & 72,4 & 72,0 & 72,8 & 73,1 \\
\hline
\end{tabular}

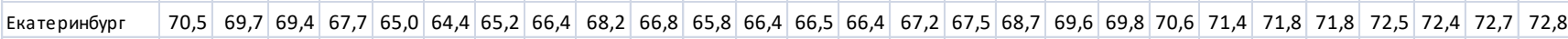
\begin{tabular}{l|l|l|l|l|l|l|l|l|l|l|l|l|l|l|l|l|l|l|l|l|l|l|l|l|l|l|l|l|l|l|l|l|l|l|l} 
Казань & 70,3 & 70,2 & 70,3 & 70,0 & 68,0 & 66,3 & 66,2 & 68,2 & 68,4 & 68,1 & 67,3 & 67,4 & 67,6 & 67,5 & 67,2 & 67,7 & 69,1 & 70,1 & 70,9 & 71,6 & 70,7 & 72,0 & 72,9 & 73,3 & 73,4 & 74,2 & 74,8 \\
\hline
\end{tabular} \begin{tabular}{|l|l|l|l|l|l|l|l|l|l|l|l|l|l|l|l|l|l|l|l|l|l|l|l|l|l|l|l|l|l|l|l|l|l|} 
Красноярск & 68,6 & 67,8 & 67,3 & 65,8 & 61,7 & 60,6 & 61,8 & 63,4 & 65,1 & 64,0 & 63,5 & 64,6 & 64,8 & 65,0 & 66,2 & 65,9 & 68,0 & 68,6 & 69,6 & 70,5 & 70,6 & 71,1 & 71,1 & 72,0 & 72,0 & 72,4 & 72,7 \\
\hline
\end{tabular}

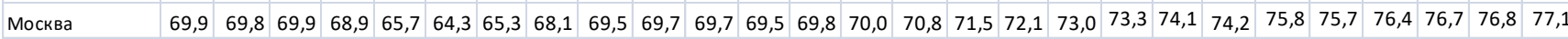

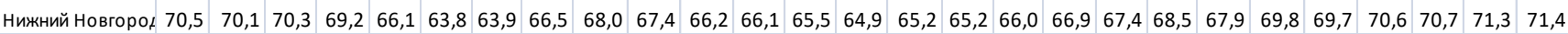
\begin{tabular}{l|l|l|l|l|l|l|l|l|l|l|l|l|l|l|l|l|l|l|l|l|l|l|l|l|l|l|l|l|l|l} 
Новосибирск & 69,9 & 69,8 & 69,9 & 68,9 & 64,9 & 63,7 & 66,0 & 66,9 & 68,2 & 68,3 & 67,9 & 67,3 & 66,9 & 66,7 & 66,8 & 66,2 & 68,0 & 68,7 & 69,7 & 70,6 & 71,0 & 71,4 & 71,4 & 71,9 & 72,0 & 72,6 & 72,8 \\
\hline
\end{tabular}

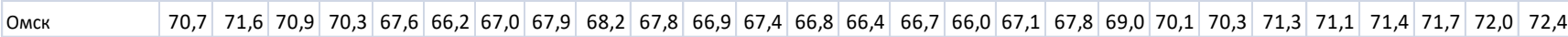
\begin{tabular}{l|l|l|l|l|l|l|l|l|l|l|l|l|l|l|l|l|l|l|l|l|l|l|l|l|l|l|l|l|l|l|l|l|l|l|l|} 
Пермь & 70,3 & 69,9 & 69,6 & 68,4 & 65,4 & 64,0 & 63,9 & 65,5 & 67,4 & 66,3 & 65,8 & 65,8 & 65,8 & 65,1 & 65,4 & 66,0 & 67,5 & 68,6 & 68,8 & 69,3 & 69,8 & 70,7 & 70,9 & 71,6 & 71,6 & 71,5 & 72,0 \\
\hline
\end{tabular} \begin{tabular}{|l|l|l|l|l|l|l|l|l|l|l|l|l|l|l|l|l|l|l|l|l|l|l|l|l|l|l|l|l|l|l|l|l|l|l|l} 
Ростов-на-Дону & 70,1 & 69,4 & 69,0 & 68,7 & 66,7 & 65,7 & 65,7 & 67,2 & 68,5 & 68,9 & 68,1 & 67,7 & 67,6 & 67,9 & 68,6 & 69,0 & 69,0 & 70,2 & 71,0 & 71,9 & 72,1 & 72,7 & 73,2 & 73,6 & 73,5 & 74,2 & 74,1 \\
\hline
\end{tabular}

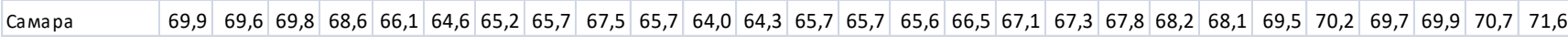
\begin{tabular}{|l|l|l|l|l|l|l|l|l|l|l|l|l|l|l|l|l|l|l|l|l|l|l|l|l|l|l|l|l|l|l|l|l|l|l|l|l}
\hline Санк-Петербург & 70,3 & 69,8 & 69,6 & 68,2 & 63,8 & 63,9 & 65,8 & 68,3 & 69,8 & 67,9 & 66,7 & 66,9 & 67,1 & 67,1 & 67,5 & 68,0 & 69,3 & 70,4 & 71,0 & 71,8 & 72,1 & 73,1 & 73,4 & 74,2 & 74,6 & 74,4 & 74,9 \\
\hline
\end{tabular}

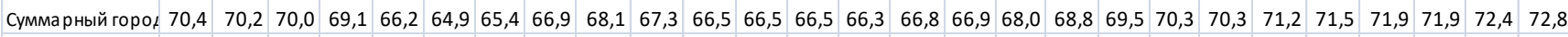

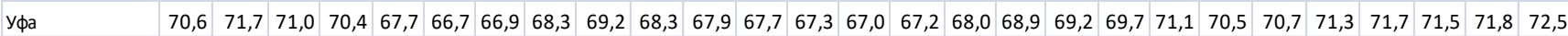
\begin{tabular}{|l|l|l|l|l|l|l|l|l|l|l|l|l|l|l|l|l|l|l|l|l|l|l|l|l|l|l|l|l|l|l|}
\hline челябинск & 70,6 & 70,5 & 70,5 & 69,2 & 66,3 & 64,8 & 65,1 & 67,0 & 68,7 & 67,5 & 66,5 & 66,6 & 66,3 & 66,4 & 67,0 & 66,9 & 68,2 & 69,7 & 69,8 & 70,7 & 70,9 & 71,3 & 71,2 & 71,7 & 71,7 & 72,0 & 72,4 \\
\hline
\end{tabular} 
Приложение 5. Среднее значение ожидаемой продолжительности жизни при рождении и величина стандартного отклонения для 11 городов-миллионников, 19892016, годы

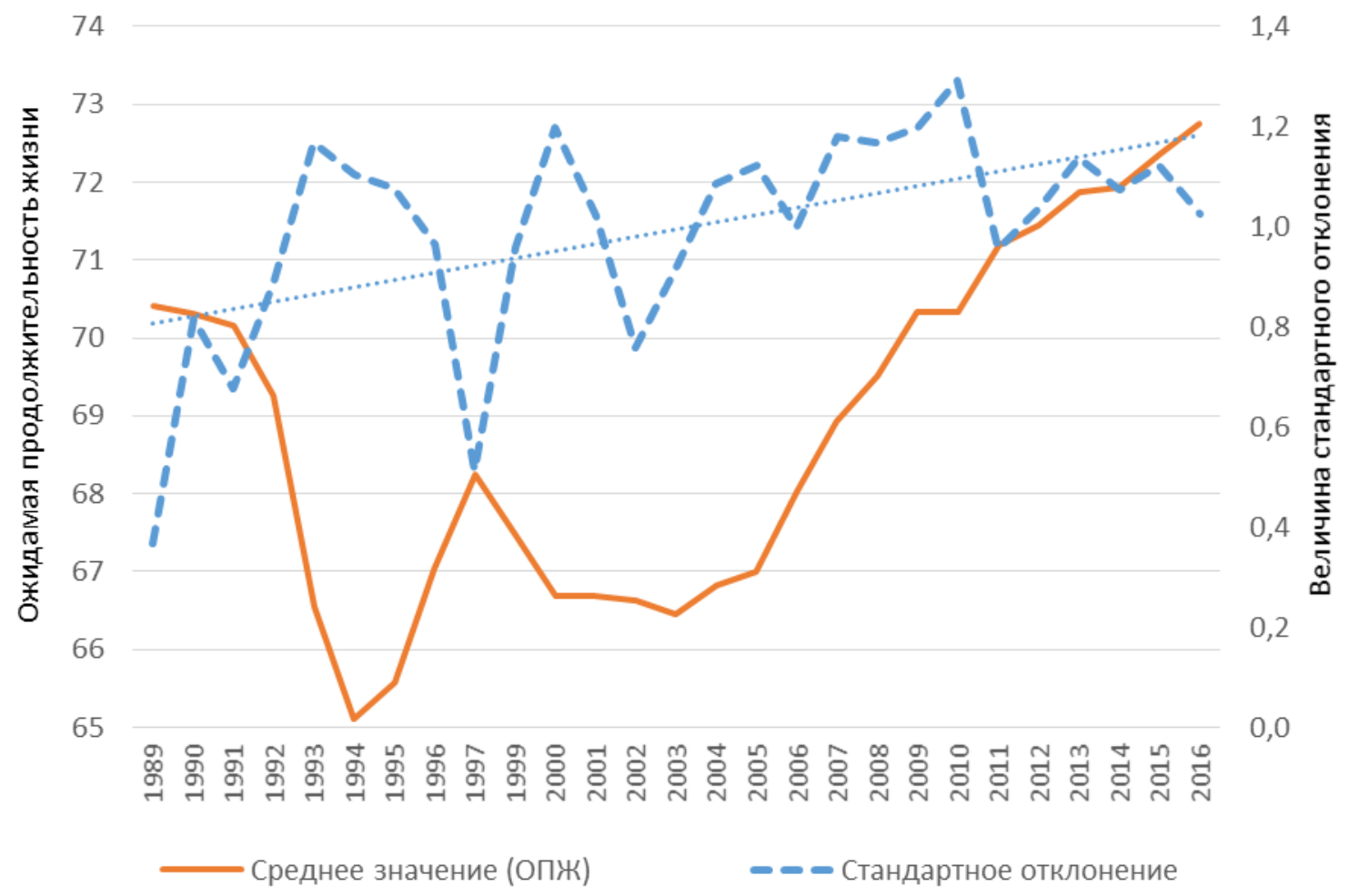

Приложение 6. Ожидаемая продолжительность жизни при рождении в Москве, Московской области, Санкт-Петербурге, Ленинградской области в 1989 и 2016 г., годы

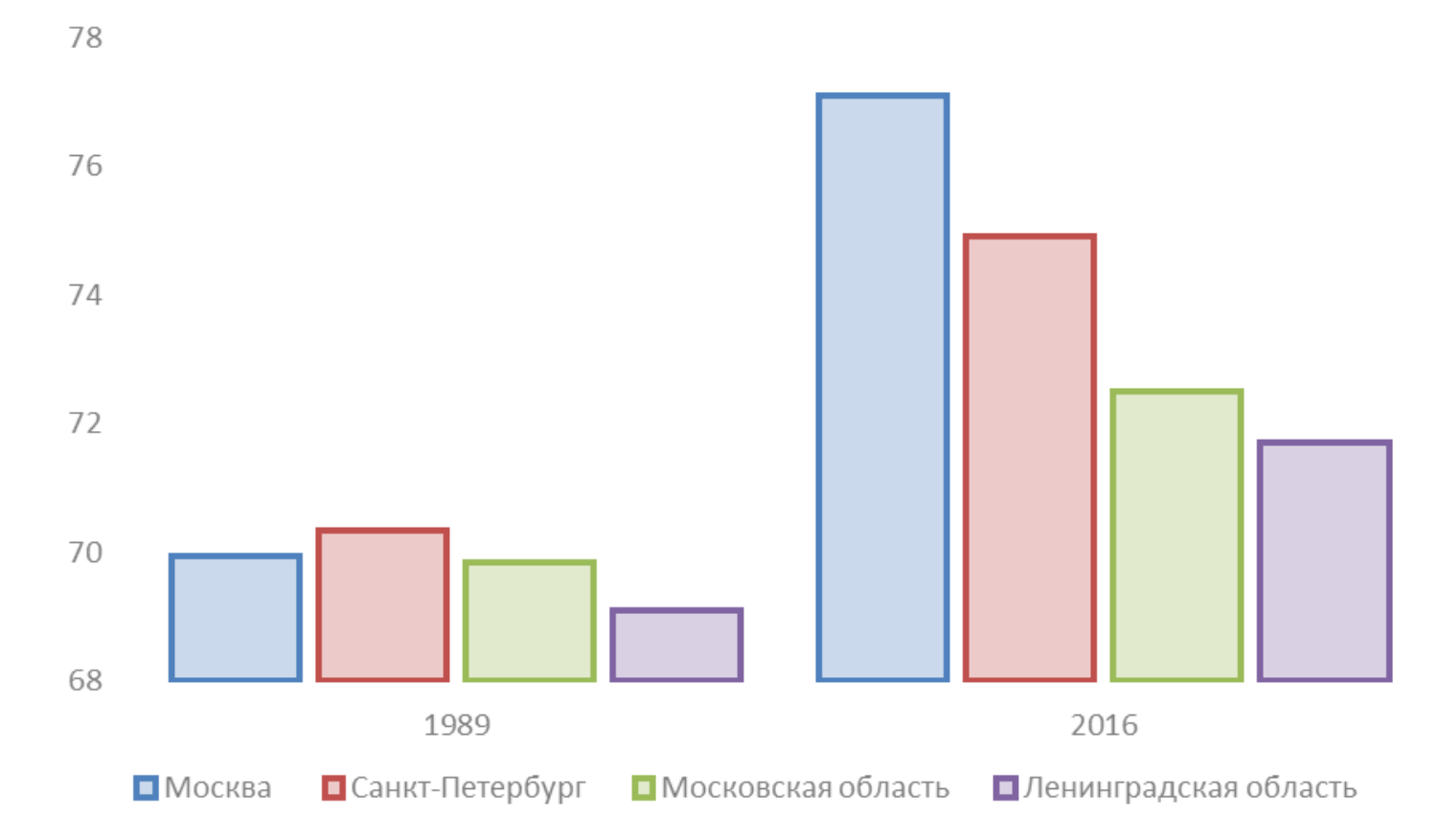




\section{Приложение 7. Валовой городской/региональный продукт (по ППС) на душу населения, доля региональных центров в населении и экономике регионов (в \%), 2015}

\begin{tabular}{|c|c|c|c|c|c|c|}
\hline региональный центр & 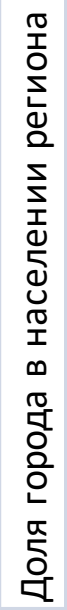 & 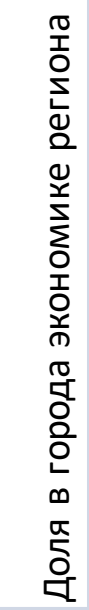 & 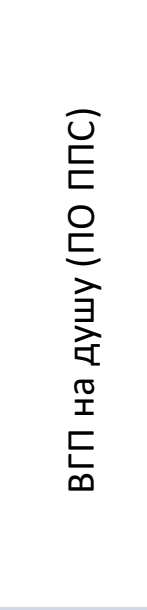 & $\begin{array}{c}\text { Без учета } \\
\text { регионального центра }\end{array}$ & 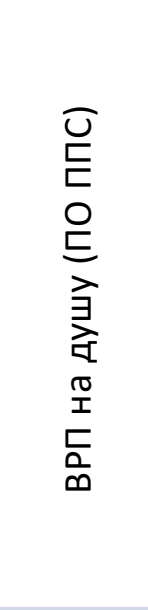 & 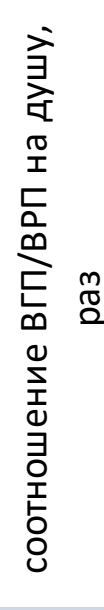 \\
\hline Воронеж & 44 & 53 & 443415 & Воронежская область & 308789 & 1,4 \\
\hline Волгоград & 40 & 52 & 412512 & Волгоградская область & 247458 & 1,7 \\
\hline Ростов-на-Дону & 26 & 51 & 544149 & Ростовская область & 186162 & 2,9 \\
\hline Уфа & 27 & 42 & 529585 & Республика Башкортостан & 278678 & 1,9 \\
\hline Казань & 31 & 29 & 493054 & Республика Татарстан & 550379 & 0,9 \\
\hline Пермь & 39 & 48 & 503968 & Пермский край & 348356 & 1,4 \\
\hline Нижний Новгород & 39 & 67 & 576344 & Нижегородская область & 181284 & 3,2 \\
\hline Самара & 36 & 47 & 510516 & Самарская область & 333787 & 1,5 \\
\hline Екатеринбург & 33 & 48 & 600234 & Свердловская область & 326130 & 1,8 \\
\hline Красноярск & 37 & 35 & 546445 & Красноярский край & 585336 & 0,9 \\
\hline Новосибирск & 57 & 73 & 465241 & Новосибирская область & 234433 & 2,0 \\
\hline Омск & 59 & 77 & 467445 & Омская область & 199093 & 2,3 \\
\hline Челябинск & 34 & 45 & 501040 & Челябинская область & 310423 & 1,6 \\
\hline Суммарный город & 37 & 48 & 509167 & Суммарный регион & 320640 & 1,6 \\
\hline Москва & 63 & 78 & 804822 & Московская область & 389152 & 2,1 \\
\hline Санкт-Петербург & 75 & 79 & 598312 & Ленинградская область & 458943 & 1,3 \\
\hline Все города-миллионники & & & 633613 & $\begin{array}{l}\text { Остальная территория } \\
\text { России (без СКФО и КФО) }\end{array}$ & 372607 & 1,7 \\
\hline
\end{tabular}

Примечание: Для Москвы и Санкт-Петербурга доля от совокупного населения этих городов и окружаюших их областей (Московской и Ленинградской) соответственно.

Источники: Валовой городской продукт - Рейтинг столичных городов России от Фонда «Институт экономики города» ${ }^{10}$. Валовой региональный продукт - данные Росстата. Паритет покупательской способности по городам - «Индекс стоимости жизни по отдельным городам Российской Федераиии» ${ }^{11}$. Остальное - расчеть автора.

${ }^{10}$ URL: http://www.urbaneconomics.ru/centr-obshchestvennyh-svyazey/news/reyting-stolichnyh-gorodov-rossii-otfonda-institut-ekonomiki\#_ftn1 (дата обращения: 27.10.2018).

${ }^{11}$ Росстат. URL: http://www.gks.ru/free_doc/new_site/prices/isj/files/itogi_isj.pdf (дата обращения: 27.10.2018). 